\title{
Passive temperature tomography experiments to characterize transmissivity and connectivity of preferential flow paths in fractured media
}

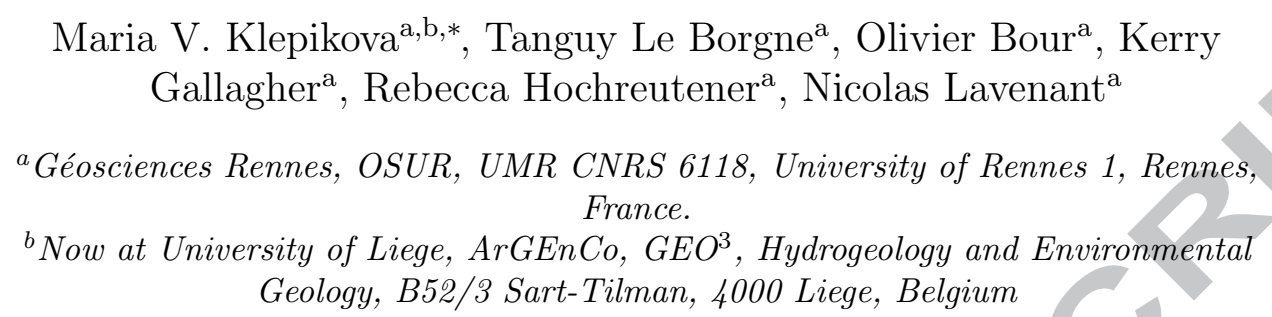

\section{Abstract}

The detection of preferential flow paths and the characterization of their hydraulic properties are major challenges in fractured rock hydrology. In this study, we propose to use temperature as a passive tracer to characterize fracture connectivity and hydraulic properties. In particular, we propose a new temperature tomography field method in which borehole temperature profiles are measured under different pumping conditions by changing successively the pumping and observation boreholes. To interpret these temperaturedepth profiles, we propose a three step inversion-based framework. We consider first an inverse model that allows for automatic permeable fracture detection from borehole temperature profiles under pumping conditions. Then we apply a borehole-scale flow and temperature model to produce flowmeter profiles by inversion of temperature profiles. This second step uses inversion to characterise the relationship between temperature variations with depth and borehole flow velocities (Klepikova et al., 2011). The third inverse step,

\footnotetext{
${ }^{*}$ Corresponding author

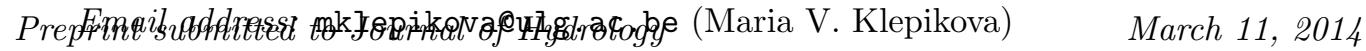



47 tomography methods in fractured media. However, spatial resolution of the 48 inferred tomograms strongly depends on the number of observation intervals

which exploits cross-borehole flowmeter tests, is aimed at inferring interborehole fracture connectivity and transmissivities. This multi-step inverse framework provides a means of including temperature profiles to image fracture hydraulic properties and connectivity. We test the proposed approach with field data obtained from the Ploemeur (N.W. France) fractured rock aquifer, where the full temperature tomography experiment was carried out between three 100 meter depth boreholes 10 meters apart. We identified several transmissive fractures and their connectivity which correspond to known fractures and corroborate well with independent information, including available borehole flowmeter tests and geophysical data. Hence, although indirect, temperature tomography appears to be a promising approach for characterizing connectivity patterns and transmissivities of the main flow paths in fractured rock.

Keywords: Temperature, Fracture, Borehole Velocity, Inverse Model

\section{Introduction}

The accurate prediction of fluid flow in fractured media is a challenging problem, as flow may be localized in few small fractures with heterogeneities at all scales (e.g. Berkowitz, 2002). The classical approach to infer detailed flow properties relies on the identification of the flowing fractures followed by hydraulic testing with packers (e.g. Shapiro and Hsieh, 1998). Recent numerical developments (e.g. Yeh and Liu, 2000; Brauchler et al., 2003; Illman et al., 2009; Berg and Illman, 2013) have significantly improved hydraulic 
72

(Sharmeen et al., 2012). Furthermore, this approach requires the installation of packers which is often not possible. To avoid these practical issues, we can consider other types of data that can be more easily obtained and that are directly sensitive to ground water flow.

Temperature data meet these conditions as geothermal heat can be considered as a natural tracer of groundwater flow (Anderson, 2005; Saar, 2011). Furthermore, temperature profiles can be obtained easily and continuously in space by logging a temperature probe in the observation borehole. The use of fiber optic technology can also greatly improve the temporal and spatial coverage of borehole temperature measurements (Read et al.,2013). Temperature data have often been used for inferring vertical or horizontal groundwater flow velocities assuming homogeneous aquifer properties (Bredehoeft and Papadopulos, 1965; Reiter, 2001; Anderson, 2005; Saar, 2011).

In fractured rocks, abrupt temperature changes are often observed at specific depths (e.g. Ge, 1998; Bense et al., 2008; Chatelier et al., 2011). When groundwater flow occurs within a permeable fracture, it may perturb the temperature profile within and around the fracture due to advected flow carrying either warmer or cooler fluid ( $G e, 1998)$. In large-scale faults, velocities can be large enough to influence the regional heat flux distribution (Deming, 1993; Ge, 1998; Anderson, 2005; Saar, 2011). Moreover, ambient flow in boreholes themselves, that arises due to the difference in hydraulic heads between fractures intersecting the borehole, affects temperature borehole logs (Bidaux and Drogue, 1993; Pehme, 2010; Klepikova et al., 2011). A few studies have considered borehole temperature profiles in fractured rocks under induced fluid flow conditions (Flynn, 1985; Silliman, 1989). Among them 
Silliman (1989) argued that temperature anomalies produced by pumping in adjacent boreholes can be used for initial estimates of fractures connecting a given 'pumping-observation' borehole pair. Few of these studies, however, were able to quantify the fracture hydraulic properties or describe how these fractures form different flow paths. This is the objective of this study.

Recently, we have shown how borehole temperature gradients may be sensitive to vertical borehole flow velocities (Klepikova et al., 2011). By applying a fluid flow and heat transfer forward numerical model, we were able to obtain borehole flow profiles under ambient, pumping (while pumping at the top of the borehole) and cross-borehole (while pumping in neighboring boreholes) flow conditions from borehole temperature-depth profiles. Furthermore, such flow profiles can be used to characterize the connectivity and hydraulic properties of the main flow paths in fractured rock (Paillet, 1998; Le Borgne et al., 2006). The method is based on the idea that pumping modifies hydraulic heads in flow paths intersecting a pumping borehole, which in turn produce changes in vertical borehole flow in observation boreholes. In a recent study, a new inversion method was developed to invert such borehole flow data. This approach, referred as flow tomography (Klepikova et al., 2013), was successful in estimating inter borehole fracture hydraulic properties as well as fracture connectivity on synthetic examples. Here, we propose to investigate how both approaches may be coupled to invert borehole temperature data in different flow conditions to estimate fracture connectivity and hydraulic properties between pairs of boreholes.

In this contribution, we propose a multi-stage inversion framework to interpret temperature measurements obtained during sequential cross-borehole 
pumping tests. We propose to call such experiments as passive temperature tomography experiments. The term "passive" means that temperature is used as a passive tracer without any heat injection, in contrast to the approach taken in other recent works (Leaf et al., 2012; Read et al., 2013; Wagner et al., 2013). Although this study makes use of the methodologies presented in (Klepikova et al., 2011) and (Klepikova et al., 2013), it presents three novelties with respect to these previous works. First, in the present study we propose a new method for automatic inversion of borehole temperature profiles that significantly facilitate data interpretation. The tomography approach based of borehole temperature measurements presented here is analogous to the flow tomography approach (Klepikova et al., 2013). However, an important advantage of this new method over direct flow measurements is that temperature can be measured more easily and continuously. Finally, this study presents the first application of this method using a tomographic approach in a fractured rock site.

In the first part we briefly review the source of temperature variations in the subsurface and examine under which conditions and assumptions our inverse approach may be applied. We then present the methods used in the inversion procedure. In the third part, we describe the experimental site and the temperature tomography experiment conducted. Finally, we present and discuss the results of the application of the inverse approach to three boreholes from the experimental field site. 


\section{Background and Methodology Proposed}

In the near surface, temperature-depth profiles are influenced by seasonal temperature variations of the land surface. Typically, this zone includes the first ten meters below the ground, although this depends on the local thermal properties. Below this depth, the temperature gradient is influenced by the heat flux, the thermal conductivity of rocks (Freifeld et al., 2008), radioactive heat sources (Perry et al., 2006) and longer term climate variations (e.g. Ferguson, 2006). Moreover, depending on hydrogeological parameters, groundwater flow may have a significant effect on the subsurface temperature regime (e.g. Anderson, 2005; Ferguson, 2006). To characterize the factors that control heat transfer in the subsurface, precise measurements of temperature as a function of depth should be considered.

In this study we focus on permeable fractured rocks in the upper crust (typically above 200 meters deep), where advection can have a significant effect on the subsurface temperature. We assume that the temperature gradient in the regional rock mass increases monotonically (i.e. constant geothermal gradient) (Klepikova et al., 2011). Given typically small temperature ranges for this depth, the dependence of viscosity on temperature is neglected. In such media induced or natural localized fracture flow generally creates local temperature anomalies. An example of flow and temperature pattern for two boreholes connected by one main flow path under ambient, single and cross-borehole pumping conditions is shown in Figure 1. In such a system, heat is carried by vertical borehole flow and dissipates to the surrounding rocks. Hence, borehole flow under ambient (Figure 1A) and pumping conditions (Figure 1B) significantly disturb the equilibrium bore- 
hole temperature profiles.

Ambient vertical borehole flow is induced by differences in hydraulic head between the different flow paths that intersect observation boreholes (e.g. Pehme, 2010; Klepikova et al., 2011). These differences in hydraulic heads are in general due to regional flow conditions (e.g. Elci et al., 2001) and the resulting vertical borehole flow may significantly disturb the temperature profile (e.g. Chatelier et al., 2011) (well 1, Figure 1A). When pumping in one of the wells, hydraulic head changes occur in the flow path connected to the pumping well. The flow paths connecting a borehole pair transmit hydraulic head variations to the neighbor borehole. This difference in hydraulic heads, in turn, depends on the transmissivities of the connecting fractures. For instance, in Figure 1B the upflow in the observation well 1 is maximum since only the upper fracture is connected and transmits the drawdown induced by pumping, implying a temperature increase in the well 1 in response to pumping from the well 2. In the well 2 (Figure 1B), an increase of the flow velocity above flowing fractures in the pumping borehole implies that the water flowing in the borehole has less time to exchange heat with surrounding rocks hence it also implies temperature profile perturbations.

Here we propose a multi-stage tomography approach based on an inverse framework for the interpretation of temperature profiles under combinations of pumping conditions to infer the full connectivity pattern as well as fracture hydraulic properties. The inversion framework proposed in this study has three main steps:

1. Automatic detection of fracture zones intersecting each borehole by applying changepoint modelling to temperature profiles under ambient 
flow conditions and steady pumping flow conditions.

2. Coupled fluid flow-heat transfer modelling: inversion of temperature profiles under ambient, single and cross-borehole flow conditions to derive flow profiles.

3. Estimation of fracture hydraulic properties and connectivity between and around each borehole pair by applying flow tomography to ambient, single and cross-borehole pumping flowmeter profiles obtained from the previous step.

The approach is summarized in Figure 2. In the following sections we detail the main steps.

\subsection{Permeable Fracture Identification at Borehole Scale}

The first step in inferring the flow pattern between a borehole pair is the detailed characterization of flow properties at the borehole scale. Several methods may be used for identification of permeable/transmissive fractures at the borehole scale. These include, for example, geological/geophysical methods (Genter et al., 1997), such as the inspection of continuous core, caliper data, acoustic and optical televiewing (Barton and Zoback, 1992) and electrical resistivity measurements (Keys, 1979). Other methods include hydraulic testing, such as flowmeter tests (Paillet, 1998), including heat-pulse flowmeter(e.g. Le Borgne et al., 2007), impeller tests (e.g. Newhouse, 2005), high spatial resolution temperature profiling (Mwenifumbo, 1993; Barton et al., 1995) and flexible liner profiling (Pehme, 2010, 2013).

In this study, we propose an automatic permeable fracture identification method based on borehole temperature profiles, that takes the advantage 
of the close relationship between the borehole temperature gradient and the vertical borehole flow velocity (Pehme, 2010; Klepikova et al., 2011). An illustration of temperature profiles under ambient and pumping flow conditions is given in Figure 1. In this example, abrupt changes in temperature gradient occur at depths where transmissive fractures intersect the borehole. As borehole flow in fractured aquifers is characterized by intervals of constant flow between transmissive fractures (Paillet, 1998), inflow points for each borehole can be therefore identified by inspection of temperature profiles.

In the field, however, multiple sources of error such as uncertainty about rock thermal diffusivity, changes in borehole diameter, multiple fracture zones and temperature measurement errors, may influence temperature data (Klepikova et al., 2011). The noise in the temperature measurements related to these factors complicates the identification of changes in temperature gradient trends and the detection of flowing fractures. To interpret the temperature-depth profiles objectively, we apply a recently proposed changepoint model (Gallagher et al., 2011). Changepoints can be defined as abrupt changes in trends (such as the mean, gradient or any function) over depth or time. Between changepoints it is assumed that underlying trends in the data are either constant or vary linearly with depth. The goal is to infer the location of changepoints (as well as the noise variance associated with each dataset if desired) in a noisy data series without a priori knowledge of the number of changepoints. Ideally, then, changepoint modelling allows us to identify inflow and outflow zones from temperature profiles.

The approach uses transdimensional Markov chain Monte Carlo to sam- 
ple many possible solutions with different numbers and locations of changepoints and noise estimates which are either accepted or rejected, based on probabilistic criterion (Gallagher et al., 2011). In general, identification of the location and number of changepoints is directly influenced by the noise level in the data and the variability of the observations about the mean between changepoints is indicative of the level of noise. Thus, data with lower noise tend to produce a model with many changepoints, while models with fewer changepoints will be acceptable for data with higher noise. The approach is formulated in a Bayesian framework, which naturally balances the noise level with the complexity of the changepoint structure (Gallagher et al., 2011). Therefore, given a choice between simple and complex models that provide a similarly adequate fit to the observed data, the models with fewer changepoints will be favored. We demonstrate that application of changepoint model to temperature profiles allows for automatic fracture detection in a field example. Note, that this result can have also a practical implication for hydrocarbon recovery, where temperature logs are commonly used to estimate fluid inflow during hydrocarbon production (e.g. Williams et al., 2000).

\subsection{Inverse Modeling of Borehole Temperature Profiles for Flow Estimation} The second step is the inversion of borehole temperature profiles to flow profiles. For a borehole with no flow, the downhole temperatures are assumed to follow the geothermal gradient while a reduced temperature gradient implies an increase of the flow velocity under single or cross-borehole flow conditions (Klepikova et al., 2011). In order to study flow and heat transfer at the borehole scale, we use a numerical model described in detail in Klepikova 
245

et al. (2011).

This model considers a cylindrical borehole (with a radius fixed to $r_{0}$ ) surrounded by the rock matrix. The borehole is divided into sections according to the position of flowing fractures inferred from the changepoint modeling (Figure 3). Note, that we do not model the fracture outside the borehole. The model includes heat advection in the borehole with a constant vertical laminar flow and heat dissipation in the surrounding rock matrix. The heat transfer equation under steady state conditions is given by

$$
\nabla \cdot\left(\alpha_{i} \nabla \theta\right)-v \nabla \theta=0
$$

where $\theta$ is temperature, $v$ is the borehole flow velocity, $i=\{$ Fluid, Rock $\}$, $\alpha_{i}=k_{i} / \rho_{i} C_{i}$ is the thermal diffusivity, $k_{i}$ is the thermal conductivity, $C_{i}$ is the heat capacity, and $\rho_{i}$ is the density. At the bottom of each borehole section we impose the borehole flow as the sum of all fractures inflows and outflows below the modeled section $\left(Q_{f r}\right)$. The inflow temperatures (here the bottom temperature for each section) are taken from the measured temperature profile. The rock temperature at the outer vertical boundary is taken from the temperature profile measured in the borehole not affected by vertical flow (the ambient temperature in the rock). The boundary condition at the lower boundary is taken as a background geothermal heat flux (Figure $3)$.

$$
Q=-k_{\text {rock }} \gamma
$$

where $\gamma$ is the background geothermal gradient. The temperature at the up247 per boundary is taken as the surface temperature (or from other constraints ${ }_{248}$ such as the temperature of a sub-horizontal large-scale fracture). 
In this study we propose a new method for automatic inversion of borehole temperature profiles, that significantly facilitates data interpretation. In order to invert temperature profiles to infer flow profiles, we couple the forward model of heat and fluid flow at the borehole scale (Klepikova et al., 2011) with an optimization algorithm. The inverse problem consists of estimating the vertical borehole flow velocities that perturb the temperature profiles observed under different flow conditions. The misfit function, FO, which evaluates the difference between direct model simulations and temperature measurements, is given by

$$
F O=\frac{1}{\sigma_{\theta}^{2}} \frac{1}{N_{\theta}} \sum_{1}^{N_{\theta}}\left(\theta_{\text {obs }}-\theta_{\text {mod }}\right)^{2}
$$

where $\theta_{o b s}$ are the observed temperatures, $\theta_{\text {mod }}$ are the temperatures predicted by the model, $\sigma_{\theta}$ is the noise variance associated with temperature data and $N_{\theta}$ are the number of temperature observations. As we show later, the typical objective function for this problem is convex and has a global minima. The optimization problem is solved by the Nelder-Mead Simplex (NMS) algorithm incorporated in the MATLAB optimization Toolbox (Lagarias et al., 2011). The NMS algorithm is a nonlinear fast local search method that does not require derivatives of the objective function and is suited to our problem.

The uncertainty in the flow velocity values obtained from temperature profiles depends on the length of the borehole flowing sections, the temperature tool precision, and the flow velocity (Klepikova et al., 2011). In order to consider the whole range of possible flow velocities for which the difference between the simulated and measured temperature is less than the relative 
accuracy of the probe, the objective function was normalized to the data error (Equation 6). Thus the magnitude of the data errors influence the value of the objective function and the convergence criteria is reached when the objective function value equals one. Then, when we fit the data, on average, to within the error, all the solutions for which the objective function value is in the order of one are acceptable.

\subsection{Site Scale Flow Inverse Modeling}

Once the borehole flow profiles have been inferred from the temperature profiles, these can be used in order to estimate transmissivities of hydraulically active fractures between and around the pumping and observation boreholes (Paillet, 1998; Le Borgne et al., 2007; Paillet et al., 2012). At the borehole scale, pumping induces flow in the different fractures intersecting the pumping borehole (Figure 1B). The resulting vertical flow depends on fracture transmissivities locally to the borehole. At larger scale, pumping induces hydraulic head variations in flow paths, which in turn drives vertical flow variations between the fractures intersecting the observation borehole. The induced vertical flow in the observation borehole depends on the different transmissivities of connecting fractures. In particular, the magnitude and the direction of the vertical flow velocity depends on the difference between transmissivities of fractures that connect the borehole as well as transmissivities of fractures that interconnect fractures connected to the borehole (Klepikova et al., 2013).

Fracture networks often have several sets of fracture connections and interpretations of the results are not straightforward. Recently, we have proposed an inverse modelling framework for flow tomography data that invert 
single- and cross-borehole flow profiles in order to estimate transmissivities of hydraulically active fractures between and around the pumping and observation boreholes (Klepikova et al., 2013). This inverse modelling approach uses a 3-D steady state numerical flow model (with 2-D flow in each fracture) to reproduce borehole flow profiles and borehole drawdowns in a fracture network. We assume a Darcy flow in the fractures, and the volume flow rate per unit fracture length on the fracture is given by

$$
u=-\frac{k}{\mu} d \nabla p
$$

where $k$ describes the fracture permeability $\left(m^{2}\right), d$ is the fracture aperture $(m)$. Each fracture is characterized by a value of transmissivity $T$, which is given by

$$
T=d \frac{k \rho g}{\mu}
$$

We apply zero-head boundary conditions, that means that no ambient flow takes place in the boreholes. Hence, the model results can be compared to field data, with the ambient flow profile substracted from the pumping profiles (Paillet, 1998). In the following flow models, the fracture aperture is fixed at $d=1 \cdot 10^{-3} \mathrm{~m}$, which is a realistic value as deduced from tracer tests conducted on the same site. To estimate the fracture transmissivities from the cross-borehole flow profiles inferred from the temperature profiles and drawdown measurements we coupled the direct flow model with a quasiNewton optimization algorithm. The misfit function, FO, which evaluates the difference between flow model simulations and observations, is given by

$$
F O=\frac{1}{\sigma_{s}^{2}} \frac{1}{N_{s}} \sum_{0}^{N_{s}}\left(s_{o b s}-s_{m o d}\right)^{2}+\frac{1}{\sigma_{v}^{2}} \frac{1}{N_{v}} \sum_{0}^{N_{v}}\left(v_{o b s}-v_{m o d}\right)^{2}
$$


where $v_{o b s}$ and $s_{o b s}$ are the flowmeter and drawdown observations, $\sigma_{v}$ and $\sigma_{s}$ are data errors for flow and drawdown respectively, $N_{v}$ and $N_{s}$ are the numbers of observations for flow and drawdown respectively, $v_{\text {mod }}$ and $s_{\text {mod }}$ are the velocity and drawdown predicted by the model.

We use a simplified fracture network model that attempts to reproduce basic fracture network connectivity without representing explicitly the complete fracture geometry (length, orientation, dip). Solving the fracture network geometry is not expected to be possible without additional geophysical data and so we refer to the effective or apparent connectivity to highlight the simplification. In the fracture network model, the observation and pumping boreholes are both intersected by horizontal fractures that represent fractures identified previously at borehole-scale (Section 2.1). The horizontal fractures are connected by a vertical fracture equidistant from both boreholes, which allows to take into account cross connections between fractures. The apparent or effective connectivity between boreholes is simply controlled by attributing different values of transmissivity to the different sections of the vertical fracture.

An example of the simplified fracture network is given in Figure 2d. We first define local transmissivities of each fracture zone intersecting the observation and pumping boreholes $\left(T_{B 1-1,2}\right.$ and $T_{B 2-1,2}$ in Figure $\left.2 \mathrm{~d}\right)$ through the inversion of ambient and steady pumping single-borehole flow profiles. In this case the number of parameters $\left(T_{B 1-1,2}\right.$ and $\left.T_{B 2-1,2}\right)$ equals to the number of observations (1 drawdown and 1 vertical borehole flow velocity for each well). Then, the inverse approach adjusts transmissivities of the different sections of the vertical fracture $\left(T_{1}, T_{2}\right.$ and $T_{3}$ in Figure $\left.2 \mathrm{~d}\right)$, so 
that the simulated cross-borehole profile and drawdown in observation well matches the data. In order to reduce the uncertainty in the model calibration, we perform a joint inversion of two pumping tests where the pumping and observation boreholes are reversed for each pair of boreholes. We thus use 4 observations $\left(s_{1}, s_{2}, v_{1}\right.$ and $\left.v_{2}\right)$ in order to determine 3 parameters. Furthermore, we believe that more complex fracture connection patterns in the interval between the boreholes could be approximated by combination of basic kinds of connections and we introduce an order of complexity that matches the information content of the data. These steps allow the inference of the apparent connectivity and transmissivities of the main flow paths as well as the transmissivity of fractures that connect the flow paths but do not cross the boreholes.

\section{Experimental Setting}

\subsection{Experimental Site}

The temperature tomography experiments were carried out within a fractured rock aquifer at the test-site Stang er Brune (Ploemeur, France) (Le Borgne et al., 2007). The site consists of 4 boreholes: borehole B1 (83 m deep), boreholes B2 and B3 (100 $m$ deep) and borehole F22 (70 $m$ deep). B1, $\mathrm{B} 2$ and $\mathrm{B} 3$ form a triangle within a radius of $10 \mathrm{~m}$ and $\mathrm{F} 22$ is $30 \mathrm{~m}$ from this triangle (Figure 4A). The geology of the site is characterized by a gently dipping contact between granite and overlying micaschists. This contact zone intersects boreholes at the following depths: B1 at $38 m$, B2 at $37 m$, B3 at $37.5 \mathrm{~m}$, and F22 at $13 \mathrm{~m}$. Both hydrological and borehole data (Le Borgne et al., 2007) demonstrate the presence of a shallow fracture within a mica-schist 
formation dipping parallel to the contact zone between granite and overlying micaschists and intersecting all the boreholes at the site. Moreover, B1, B2 and B3 boreholes are intersected by several permeable fractures within the granite formation (Le Borgne et al., 2007; Dorn et al., 2012, 2013). The site is located near a lake and there is a regional or watershed scale upward flow at this location, resulting from hydraulic head difference between the deepest confined fractures in granite and the upper mica schist. Flow measurements demonstrated that F22 borehole is not affected by vertical flow. In the next section, we demonstrate that temperature measurements on the site are strongly influenced by these hydrogeological conditions.

\subsection{Borehole Temperature Profiles in Ambient Conditions}

Temperature measurements were conducted under ambient flow conditions with a temperature logging device, the Idronaut CDT 302 Multi-Parameter Probe with a tool precision of $0.005^{\circ} \mathrm{C}$ (Figure $4 \mathrm{C}$ ). All four wells show abrupt changes in temperature gradient between 10 and 40 meters depth, the exact depth depending on the borehole. Below this depth, the temperature gradient is relatively low and variable between the different boreholes. Above this depth, the temperature gradient changes to conform to the surface temperature, which is fixed by the mean annual surface temperature equal to about $T_{\text {surf }}=12.5^{\circ} \mathrm{C}$.

The observed site-scale temperature field is typical of the one perturbed by a gently dipping structure where fluids of greater temperature than the surrounding rocks are flowing from depth to sub-surface (e.g. Ge, 1998; Saar, 2011). The corresponding flow pattern is shown in Figure 4B. For each borehole, the depths of change in gradient, F22 at $8 m$, B1 at $24 m$, B2 at 25 
$m$ and B3 at $36.5 \mathrm{~m}$, correspond to the depths of the first shallow fracture in mica-schists, which was reported by Le Borgne et al. (2007). Fluid flow in this fracture advects heat and because water in the conduit is assumed well mixed it provides a constant temperature boundary condition. Consequently, this process distorts the otherwise continuous linear geothermal profile (Saar, 2011).

Below the sub-horizontal fracture in mica-schist, the boreholes have different temperature gradients. The highest thermal gradient $\gamma=0.016^{\circ} \mathrm{C} / \mathrm{m}$ was measured in the F22 well. This borehole has no significant ambient vertical flow due to its very low permeability and so the temperature field is dominated by the upward conductive heat transfer. Thus, the F22 temperaturedepth profile may be considered representative of the temperature of the surrounding rock at the site.

While this groundwater flow in the mica-schist influences the temperature field of the whole site, the temperature gradients variations in granite seem to have much less regional influence. In boreholes B1, B2, and B3 the temperature gradients measured below 30-40 meters are typically lower than the geothermal gradient estimated from F22. This is the result of upward advective flow between flowing fractures as revealed by borehole flow logs (Klepikova et al., 2011).

Furthermore, for all boreholes a slight change in temperature gradient is observed at the depth of the contact zone between granite and micaschists (see previous section), that is shown by the black line in Figure $4 \mathrm{C}$. These thermal gradient variations are due to the higher thermal conductivity of granite compared to micaschists. Moreover, the B3 temperature profile in 
Figure 4 shows abrupt temperature changes at $45 \mathrm{~m}$ and $80 \mathrm{~m}$, which correspond to depths of fractures reported by Le Borgne et al. (2007). These anomalies are explained by the localized lateral advection of colder water within narrow fractures in granite intersecting the borehole $(G e, 1998)$. To summarize our observations, the borehole temperature distributions reflect five dominant factors:

- upward conductive heat transfer through the rocks reflected as a continuous increase of temperature with depth,

- gently dipping groundwater flow in micaschists of warmer (deeper) origin,

- advection of heat by the vertical flow in the boreholes,

- localized lateral advective transfer of water within narrow fractures,

- variations in thermal properties of rock.

\subsection{Temperature Tomography Experiments}

After measuring the ambient temperature profiles and hydraulic heads in all boreholes, three successive cross-hole pumping tests were conducted in B1, B2 and B3 with temperature monitoring in all boreholes. For the temperature tomography study, the temperature profiles need to be measured a sufficient time after pumping to ensure steady state has been reached. To monitor this, a set of 7 thermistors was centered permanently within each well. The number of transducers was chosen to be able to control all borehole sections between the flowing fractures. To record temperature variations 
with time for the given depths, the acquisition time of $20 s$ was chosen. An example of temporal evolution of temperature is given in Figure 5D. These data show that thermal steady state for each particular depth and well was reached in $1-2$ hours after switching on the pumping, depending on the pumping and observation locations. The temperature variations with time were not used in the subsequent analysis for this study. However, the interpretation of transient data could also provide other useful information, such as thermal diffusivity values.

Prior to starting the next pumping test the pressure and temperature were allowed to recover for each experiment. The first cross-borehole pumping test took place in well B3 with a pumping rate of $Q_{B 3}=154 \pm 3$ $l /$ min. Subsequently, we conducted pumping tests in B2 well (pumping rate $Q_{B 2}=136 \pm 14 \mathrm{l} / \mathrm{min}$ ), and then in B1 well (pumping rate $Q_{B 1}=77 \pm 2$ $l / \min )$. Thus, the full data set consists of 9 hydraulic heads and 9 temperature profiles: 3 ambient profiles and 6 profiles when pumping in the neighboring well. The temperature profiles were measured with a temperature logging device (The Idronaut CDT 302 Multi-Parameter Probe). During the experiment it was observed that upward temperature logs often exhibit slightly higher temperatures than downward logs. In this work we considered only downward logs, as we believe that it creates less perturbation of the temperature field. The collected steady-state temperature-depth profile are shown in Figure 5, and these clearly show the sensitivity of temperature measurements to changes in pumping conditions. 


\section{Results}

In this section, we present results of the application of the inverse modelling framework to data from Stang er Brune field site. We firstly infer the location and number of flowing fractures intersecting the boreholes by applying changepoint modelling to temperature profiles. Then, we assess inter-borehole connections properties by inverting the temperature tomography data set. Finally, we discuss the corresponding uncertainty estimates.

\subsection{Permeable Fracture Identification at Borehole Scale}

In order to detect flowing fractures intersecting the boreholes, we apply changepoint modelling e.g. (Gallagher et al., 2011) to temperature profiles under ambient and single-borehole pumping flow conditions. Figure 6 presents ambient (A) and pumping (B) temperature profiles (with a pumping rate $Q=20 \mathrm{l} / \mathrm{min}$ ) measured in B1 borehole, the inferred changepoint structures (red line) and probability distributions on the changepoint locations for both flow conditions. These change point structures were determined assuming that the noise level for these temperature data equal to the $\pm 0.005^{\circ} \mathrm{C}$, that correspond to the precision of the tool. Locations of the changepoints inferred from the temperature profile under ambient flow conditions are the following: $z=24$ and $38 \mathrm{~m}$. They correspond to the depths of the first shallow fracture in mica-schists and the depth of the contact zone between granite and mica-schists. As discussed in the section 3.2, the contrast in gradient at the depth of the first shallow fracture in mica-schists is due to constant temperature boundary condition, provided by this fracture. The change in gradient at $38 \mathrm{~m}$ in $\mathrm{B} 1$ is due to the contrast in thermal conductivity of the 
surrounding rocks. This example demonstrates that analysis of temperature profiles under ambient conditions can reveal changes in temperature gradient that are not related to flow in the borehole itself (e.g. contrast in thermal properties of rock, low transmissive fractures carrying flow of contrast temperature).

The locations of the most probable changepoints inferred from the temperature profile under pumping conditions are the following: $z=24,50.9$, 60.9 and $78.7 \mathrm{~m}$. They correspond well to fracture locations in B1, identified previously by flowmeter tests (Le Borgne et al., 2007) and ground-penetrating radar (Dorn et al., 2012). The increase in the number of inferred changepoints for the pumping conditions means that the sensitivity of the method could be improved by increasing the pumping rate. However, as discussed in Klepikova et al. (2011) there is a limited range of flow velocities for which changes in flow produces measurable changes in the thermal gradient. Thus, for too large flow velocities the temperature anomaly propagates too fast to allow for measurable loss of heat to the rock formation. For too small flow velocities, the temperature anomaly equilibrates quickly with the surrounding rock temperature. In practice, the estimated temperature changes in a given borehole section between two flowing fractures should be larger than the measurement error. For our experimental conditions, we found that the value of $Q=20 \mathrm{l} / \mathrm{min}$ is optimal as further increasing the pumping rate implies that the temperature profile would appear to be completely straight. After applying the changepoint modelling method to other boreholes, the depths of the inferred most probable changepoints are $z=24,56$ and 79 in B2 borehole and $z=35,45$ and 80 in B3 borehole. These depths are 
also consistent with fractures that were identified as being transmissive by single-borehole flowmeter tests (Le Borgne et al., 2007), demonstrating the potential of changepoint modelling in the automatic detection of the main transmissive fractures from temperature profiles.

\subsection{Inverse Modeling of Borehole Temperature Profiles for Flow Estimation}

Having detected the flowing fractures, we simulate flow and temperature advection for each borehole from the first bottom transmissive fracture up to the shallowest transmissive fracture. The rock temperature at the outer boundary of the model borehole is inferred from the temperature profile measured in F22 as it is not affected by borehole flow. The thermal properties of the rock matrix were chosen to be equal to the mean thermal properties measured in laboratory on samples from B1 borehole. Note, that we tested in our numerical model what could be the consequence of uncertainties about thermal conductivity and we found that the resulting uncertainty about velocity estimation remains within a few percent. Thus, the granite thermal conductivity is given by $k_{\text {Rock }}=3.31 \mathrm{~W} / \mathrm{m}^{\circ} \mathrm{C}$, the heat capacity of the granite is given by $C_{\text {Rock }}=738 \mathrm{~J} / \mathrm{kg}^{\circ} \mathrm{C}$. The values for water properties are given by $k_{\text {Fluid }}=0.59 \mathrm{~W} / \mathrm{m}^{\circ} \mathrm{C}$ and $C_{\text {Fluid }}=4189 \mathrm{~J} / \mathrm{kg}^{\circ} \mathrm{C}$ respectively (Incropera and DeWitt, 1996).

A typical example of the objective function versus the vertical borehole flow velocity is presented in Figure 7 . In this figure the optimal flow velocity $\left(v_{\text {opt }}\right)$ is presented for the part of temperature profile measured in B1 borehole (over the depth range $60.9-78.7 \mathrm{~m}$ ) while pumping in B2. In order to quantify the uncertainty on this flow velocity, we determine the range of possible

flow velocities $\left(v_{\min }, v_{\max }\right)$ for which the objective function is less than one 
and thus the difference between the simulated and measured temperature is less than the relative accuracy of the probe (Equation 6). The objective function is found to be most sensitive for $v=5 \cdot 10^{-4}-2 \cdot 10^{-3} \mathrm{~m} / \mathrm{s}$ flow velocity range. For larger velocities the temperature anomaly propagates too fast to allow for significant temperature change by heat loss to the rock formation. Then for flow velocities larger than $v=2 \cdot 10^{-2} \mathrm{~m} / \mathrm{s}$ the temperature profile becomes completely straight and the objective function becomes insensitive to velocity. It is difficult to affirm that we found a global minima. However, for all cases considered in this study, the objective function was found to be smooth and convex thus enable efficient minimization.

The inversion results show that vertical borehole flow occurs in all boreholes under ambient conditions. In order to check the accuracy of the estimated flow profiles, we measured flow profiles directly with heat-pulse flowmeter for some hydrodynamic conditions (ambient and during pumping in B2 borehole). The heat pulse flowmeter can measure flow velocities as small as $0.5 \mathrm{~L} / \mathrm{min}$ (Paillet, 2004). The uncertainty on the velocity values obtained from temperature profiles varies between 0.1 and $0.5 \mathrm{~L} / \mathrm{min}$ depending on the length of the borehole flowing sections and the flow velocity. The flow velocities obtained from temperature measurements are compared in Figure 8 to flow measured directly with a flowmeter under the same hydrodynamic conditions. It appears that the method allows the reliable estimation of flow velocities for a large range of flow, although the model slightly underestimates flow for larger flow velocities. A possible reason for this may be that the upper limit of the applicability of the model was reached for this particular borehole section. Overall, however, the inversion of all measured 
temperature profiles provides a complete and continuous flow velocity data set for flow tomography.

\subsection{Site Scale Flow Inverse Modelling}

We now apply the flow tomography framework in order to estimate the transmissivities of hydraulically active fractures between and around each borehole pair. To model flow between boreholes, the fracture network geometry has been simplified as described in Section 2.3 and we couple the forward model with the inverse algorithm. The partial differential equation (Equation 4) was solved with the finite element code Comsol Multiphysics 4.2a with a fine tetrahedral meshing. A set of 20 starting transmissivity models is generated for each boreholes pair to search for a minimum of the objective functions. Note that the computation time for one direct simulation is about 2 minutes, while the solution converges generally after several hundred iterations. Thus, the number of starting points was limited by computing time for these modelling runs. For each borehole pair several solutions were found to satisfy the convergence criteria. As all acceptable solutions were found to be similar (except few cases discussed below), we consider only the 'best' solution providing the minimum of the objective function. Nevertheless, we accept the possibility that some solutions may correspond to local minima of the objective function. This can be addressed to some extent by increasing the number of the starting models if desired.

The inverted parameter estimates are shown in Figures 9, 10 and 11 and synthesized in Table 1 . Our results show that fracture transmissivities at the site range from $10^{-6}$ to $2 \cdot 10^{-3} \mathrm{~m}^{2} / \mathrm{s}$, which is in general agreement with other studies at the same site (Le Borgne et al., 2007; Dorn et al., 2012, 2013). The 
obtained solution yields the best fit to measured borehole drawdowns and the flow tomography data inverted from temperature profiles. The comparison of flow tomography data, including drawdowns $s$ and variations of vertical borehole flow velocities during cross-borehole pumping $\Delta v$ in observation boreholes, and inversion results is given in Table 2. This shows that the predicted and measured flow and drawdowns values are generally in good agreement for the cross-borehole tests.

To explain qualitatively the results, we discuss the relationship between the inferred connectivity patterns (transmissivities of different sections of the vertical fracture $T_{i}$ ) and variations of vertical borehole flow velocities during cross-borehole pumping. The results for the B1-B2 borehole pair (Figure 9, Table 1) demonstrate that the most transmissive fracture connection is the one at a depth of $50 m$ that connect B1-3 and B2-2 fractures $\left(\log T_{3}=-2.8\right)$. In contrast, the deep fractures, B1-4 and B2-4, are found to be poorly connected $\left(\log T_{5}=-5.8\right)$. These results can be understood with reference to Table 2, where flow tomography data (drawdowns $s$ and variations of vertical borehole flow velocities $\Delta v$ during cross-borehole pumping tests in observation boreholes) are presented. For the B1-B2 borehole pair, we found an increase of upward flow for all sections of both boreholes. Flow in the observation well is directly towards the fracture that transmits most drawdown from the pumping well. Thus, this explains the strong connection found for B1-3 and B2-2 fractures and it implies that overall transmissivities of fractures connecting the B1-B2 borehole pair should decrease with depth. Similarly, for the B1-B3 and B2-B3 borehole pairs, an increase in upward flow in both boreholes during cross-borehole pumping tests (Table 2) implies 
good fracture connections for the shallow fracture and less connectivity of deep fractures.

For the fracture connection discussed above, the transmissivities $T_{i}$ were similar for all solution. However, for few cases the parameter estimations were found to be uncertain. In order to explain this we refer to the sensitivity analysis for flow tomography approach conducted in our recent study (Klepikova et al., 2013). This sensitivity analysis demonstrates that for small borehole flows, similar velocities can be produced by different combinations of fracture transmissivities, implying that the uncertainty about parameter estimations increases as borehole flow decreases. Thus, large flow velocities in deep borehole sections (Table 2) provide a strong constraint for deep fracture connections for the B1-B2 and B1-B3 borehole pairs. For instance, for the B1-B2 borehole pair, to maximize the difference in hydraulic heads drawing these velocities, the transmissivity of the $T_{3}$ fracture connection should be maximized, while the transmissivity of the $T_{4}$ fracture connection should be minimized. In contrast, small flow velocities in shallow borehole sections implies that the estimates of the parameters $T_{1}$ and $T_{2}$ are rather uncertain. For the fracture network connecting the B2-B3 borehole pair, small flow velocities in both wells (Table 2), do not provide a strong constraint for the interconnection fracture transmissivities and the estimations of $T_{2}, T_{3}$ and $T_{4}$ vary within two orders of magnitude.

The most transmissive fracture connections at the site can be summarized as follows:

- $B 1-B 2$ borehole pair is mainly connected through $B 1-2$ and $B 2-2$

- $B 1-B 3$ borehole pair is mainly connected through the cluster that 
consists of $B 3-1, B 3-2, B 1-1$ and $B 1-2$ fractures

- $B 2$ - B3 borehole pair is mainly connected through 2 independent clusters. The first one consists of $B 2-2, B 3-1$ and $B 3-2$, and the second one consists of $B 2-4$ and $B 3-3$.

\section{Comparison With Results From Flowmeter Tests and Ground- Penetrating Radar Data}

Analysis of fracture connections on this field site have been also conducted by Le Borgne et al. (2007), Dorn et al. (2012) and Dorn et al. (2013). Le Borgne et al. (2007) used televiewer data together with cross-borehole single packer testing and cross-borehole flowmeter testing at the site to characterize fracture hydraulic connections. Comparison with our results demonstrates that temperature based approach provides consistent results with very few exceptions. Thus, flowmeter tests and packer tests both confirm that B2 well is connected to B1 and B3 wells mostly through B2-2 fracture. The main difference concerns to the connection of B2-4 fracture zone to B1 borehole, which we find here to be poorly connected (Figure 9). Le Borgne et al. (2007) found that, although the main head variation during single packer tests is occurring in the B2-2 fracture zone in B2 when pumping in B1, the B2-4 fracture zone appears also to be connected to B1.

Dorn et al. (2012) used tracer test data combined with single-hole groundpenetrating radar (GPR) data to characterize pattern of fractures that contribute to tracer transport in between B1 and B2 wells. The images obtained confirmed the existence of a network of connected fractures including the B2-2, B2-4 and B1-4 fractures. However, fractures that contribute to tracer 
transport are not necessarily those that provide the significant contribution to flow (Dorn et al., 2012). Furthermore, for some fracture patterns, our conceptual approach introduces some constraints on fracture connections. For instance, in our approach, the B2-4 fracture can not be connected to any other fracture without being connected to the B1-4 fracture. A possible solution to tackle the problem would be the use of more realistic fracture geometry provided through geophysical data (Dorn et al., 2012).

Dorn et al. (2013) used hydraulic, tracer, televiewer and GPR reflection data to generate stochastic 3-D discrete fracture models in the vicinity of the B1 and B2 boreholes such that these fracture networks agree with all available data. They also performed flow simulations on the proposed discrete fracture networks in order to derive the effective transmissivity of hydraulic connections between the boreholes. Their values of the effective transmissivities varied in the range of $10^{-6}-10^{-3} \mathrm{~m}^{2} / \mathrm{s}$ that matches well with our estimates. For the individual hydraulic connections, they found the B1-4 - B2-2 fracture connection to be the most transmissive, and that B1-2 and B1-3 fractures are well connected to B2 borehole, which is in agreement with our results in Figure 9. As expected, the fracture network geometry inferred from GPR data is much more complex than the conceptualization used in the present study. In particularly, we didn't include in our model two fractures, intersected B2 borehole at 49 and $52 \mathrm{~m}$ depth (Dorn et al., 2013). However, as flow prediction made by our flow model are reasonnable and flow contributions of these fractures are negligible, we believe that these simplifications not change a lot in terms of fracture network transmissivity. This point emphasize that both methods are complementary: geometry can 
be constrained from geophysical data, whereas hydraulic properties can be inferred from flow tomography data.

\section{Discussions and Conclusions}

The temperature tomography approach (i.e. sequential borehole temperature logging under cross-borehole flow conditions) has been proposed here as a method to characterize the connectivity and transmissivity of preferential permeable flow paths in fractured aquifers. An inverse model framework was developed to estimate log-transformed transmissivity values of hydraulically active fractures between and around borehole pairs. We first detect the main permeable fractures through inversion of borehole temperature profiles under pumping conditions. Then we apply a borehole-scale flow and temperature model to produce flowmeter profiles by inversion of temperature profiles. Finally we invert the obtained cross-borehole flowmeter profiles in order to infer inter-borehole fracture connectivity and transmissivities.

The method proposed has been successfully applied to temperature tomography data obtained from a fractured rock aquifer. The results of application of the proposed approach to the Stang Er Brune experimental site (Ploemeur) can be synthesized as follows:

- A general flow pattern for the experimental site is proposed based on the analysis of borehole temperature profiles under ambient flow conditions.

- The inversion of single-borehole flow and cross-borehole temperature data is shown to allow the detection of the main fractures at the site and to image their hydraulic properties. 
- In some cases of multi-fracture connections it appears difficult to propose a simple conceptual model of flow and connectivity.

These first applications are encouraging in that, even though the fracture network geometry has been simplified, the estimates of fracture connectivity and hydraulic properties are generally consistent with other data sets available on this site. In the future, tracer experiments and geophysical surveys (Dorn et al., 2012) may be coupled with temperature data to assess the overall fracture network geometry and its hydraulic properties. Furthermore, a possible extension of this inverse approach could exploit simultaneous joint inversion of multiple pumping tests with more than two boreholes to identify and characterize a connected fracture cluster all over the site.

The temperature tomography approach proposed in this study has some limitations. First, the method is not sufficiently sensitive to identify all flowing fractures in a given borehole and only allows the detection of the most transmissive fractures. Second, the capacity of this approach is limited when cross-borehole pumping induces similar hydraulic head variations within flow paths connecting borehole pair. In this case, the resulting velocity in the concerned section of observation borehole is close to zero and uncertainty about corresponding parameter drastically increases. Third, as the approach is based on indirect measurements of temperature, in order to obtain detectable temperature variations, significant flow velocities are required to apply successfully the methodology proposed (Klepikova et al., 2011). Finally, it also requires the temperature to change with depth.

Although there are some limitations, we argue that the temperature tomography method is a promising alternative to hydraulic tomography tests 
that require the use of straddle packers. In particular, the temperature tomography approach was found to be clearly useful for fractured rock aquifers as Ploemeur field site (Le Borgne et al., 2006, 2007). The method is also likely to be applicable to field sites with significant flow velocities such as karst aquifers (e.g. Chatelier et al., 2011). Another interesting question of investigation is whether the method proposed could be used to characterize alluvial aquifers. However, getting necessary information in such type of environment will probably require more detailed temperature measurements. Further work is required to answer this question.

\section{Acknowledgments}

This work was supported by the European Marie Curie network IMVUL (Grant Agreement 212298), by the National Research Observatory H+, by the European Interreg IV project CLIMAWAT, and by the ANR project CRITEX, ANR-11-EQPX-0011 "Investissements d'avenir".

\section{References}

Anderson, M. P. (2005), Heat as a ground water tracer, Ground Water, 43(6), $951-968$.

Barton, C. A. and Zoback, M. D. and Moos, D. (1995), Fluid flow along potentially active faults in crystalline rock, Geology, 23(8).

Barton, C. A. and M. D. Zoback (1992), Self-Similar Distribution and Properties of Macroscopic Fractures at Depth in Crystalline Rock in the Cajon 
732

Pass Scientific Drill Hole, Journal of Geophysical Research, 97(B4), 51815200.

Bense, V. F., Person, M. A., Chaudhary, K., You, Y., Cremer, N., and S. Simon (2008), Thermal anomalies indicate preferential flow along faults in unconsolidated sedimentary aquifers, Geophysical Research Letters, 35(24), L24406, doi:10.1029/2008GL036017.

Berg, S.J., and W.A. Illman (2013), Field Study of Subsurface Heterogeneity with Steady-State Hydraulic Tomography, Ground Water, 51(1), 29-40.

Berkowitz B. (2002), Characterizing flow and transport in fractured geological media: A review, Advances in Water Resources, 25, 861-884.

Bidaux, P., and C. Drogue (1993), Calculation of low-range flow velocities in fractured carbonate media from borehole hydrochemical logging data comparison with thermometric results, Ground Water, 31(1), 19-26.

Brauchler, R., R. Liedl and P. Dietrich (2003), A travel time based hydraulic tomographic approach, Water Resource Research, 39(12), 1370, doi10.1029/2003WR002262.

Bredehoeft, J. H., and I. S. Papadopulos (1965), Rates of vertical groundwater movement estimated from the Earth's thermal profile, Water Resource Research, 1, 325-328.

Chatelier, M., S. Ruelleu, O. Bour, G. Porel, and F. Delay (2011), Combined fluid temperature and flow logging for the characterization of hydraulic structure in a fractured karst aquifer, Journal of Hydrology, 400, 377-386. 
Deming D. (1993), Regional permeability estimates from investigations of coupled heat and groundwater flow, North Slope of Alaska, Journal of Geophysical Research, 98, 16271-16286.

Dorn C., N. Linde, T. Le Borgne, O. Bour, and M. Klepikova (2012), Inferring transport characteristics in a fractured rock aquifer by combining single-hole GPR reflection monitoring and tracer test data, Water Resource Research, 48, W11521, doi10.1029/2011WR011739.

Dorn C., N. Linde, T. Le Borgne, O. Bour, and J.-R. de Dreuzy (2013), Conditioning of stochastic 3-D fracture networks to hydrological and geophysical data, Advances in Water Resources, 62, 79-89, doi10.1016/j.advwatres.2013.10.005.

Elci, A., Molz, F. J. and Waldrop, W. R. (2001), Implications of Observed and Simulated Ambient Flow in Monitoring Wells, Ground Water, 39, 853862. doi10.1111/j.1745-6584.2001.tb02473.x.

Ferguson G. (2006), Perturbation of ground surface temperature reconstructions by groundwater flow, Geophysical Research Letters, 33, L13708, doi10.1029/2006GL026634.

Flynn T. (1985), Water temperature as a groundwater tracer in fractured rock, M.S. thesis, Univ. of Arizona, Tucson.

Freifeld, B. M., S. Finsterle, T. C. Onstott, P. Toole, and L. M. Pratt (2008), Ground surface temperature reconstructions: Using in situ estimates for thermal conductivity acquired with a fiber-optic distributed 
thermal perturbation sensor, Geophysical Research Letters, 35, L14309, doi10.1029/2008GL034762.

Gallagher, K., Bodin, T., Sambridge, M., Weiss, D., Kylander, M., Large, D. (2011), Inference of abrupt changes in noisy geochemical records using transdimensional changepoint models, Earth and Planetary Science Letters, 311(1), 182-194, doi10.1016/j.epsl.2011.09.015.

Garibaldi, C., Guillou-Frottier, L., Lardeaux, J. M., Bonte, D., Lopez, S., Bouchot, V. and Ledru, P. (2010), Thermal anomalies and geological structures in the Provence basin: Implications for hydrothermal circulations at depth, Bulletin de la Société Géologique de France, 181(4), 363-376.

Ge, S. M. (1998), Estimation of groundwater velocity in localized fracture zones from well temperature profiles, Journal of Volcanology and Geothermal Research, 84(1-2), 93-101.

Genter, A., Castaing, C., Dezayes, C., Tenzer, H., Traineau, H., villemin, T. (1997), Comparative analysis of direct (core) and indirect (borehole imaging tools) collection of fracture data in the Hot Dry rock soultz reservoir (France), J. Geophys. Res., 102(B7), 1541915431.

Hess, A. E. (1986), Identifying hydraulically conductive fractures with a slow velocity borehole flowmeter, Canadian Geotechnical Journal, 23, 69-78.

Illman, W. A.,X. Liu,S. Takeuchi, T.-C. J. Yeh, K. Ando, and H. Saegusa (2009), Hydraulic tomography in fractured granite: Mizunami Underground Research site, Japan, Water Resource Research, 45, W01406, doi10.1029/2007WR006715. 
Incropera and DeWitt (1996), Fundamentals of heat and mass transfer, 4th ed., New York: Wiley.

Klepikova, M. V., T. Le Borgne., O. Bour, P. Davy (2011), A methodology for using temperature-depth profiles under ambient, single and cross-borehole pumping conditions to estimate fracture hydraulic properties, Journal of Hydrology, 407(1-4), 145-152, doi10.1016/j.jhydrol.2011.07.018.

Klepikova, M. V., T. Le Borgne., O. Bour, J.-R. de Dreuzy, Inverse modelling of flow tomography experiments in fractured media, Water Resource Research, 49(11), 7255-7265, doi10.1002/2013WR013722.

Keys, W. S. (1979), Borehole geophysics in igneous and metamorphic rocks, Trans. SPWLA Annual Logging Syrup., 20th, 407, 1-26.

Lagarias, J.C., J. A. Reeds, M. H. Wright, and P. E. Wright (1998), Convergence Properties of the Nelder-Mead Simplex Method in Low Dimensions, SIAM Journal of Optimization, 9(1), 112-147.

Leaf, A. T., D. J. Hart, J. M. Bahr (2012), Active thermal tracer tests for improved hydrostratigraphic characterization, Ground Water, 50(5), doi10.1111/j.1745-6584.2012.00913.x.

Jolivet, J., G. Bienfait, J. L. Vigneresse, and M. Cuney (1988), Heat flow and heat production in Brittany (Western France), Tectonophysics, 159, 61-72.

Le Borgne, T., Paillet, F.L., Bour, O., Caudal, J.-P. (2006), Cross-borehole 
Paillet, F. L., J. H. Williams, J. Urik, J. Lukes, M. Kobr and S. Mares ter, 44, doi10.1111/j.1745-6584.2005.00150.x.

Le Borgne, T., O. Bour, M.S. Riley, P. Gouze, P.A. Pezard, A. Belghoul, G. Lods, R. Le Provost, R. B. Gresswell, P. A. Ellis, E. Isakov, and B. J. Last (2007), Comparison of alternative methodologies for identifying and characterizing preferential flow paths in heterogeneous aquifers, Journal of Hydrology, 345(3-4), 134-148, doi10.1016/j.jhydro1.2007.07.007.

Mwenifumbo, C. J. (1993), Temperature logging in mineral exploration, Journal of Applied Geophysics, 30, 297-313.

Newhouse, M. W., J. A. Izbicki and G. A. Smith (2005), TComparison of velocity-log data collected using impeller and electromagnetic flowmeters, Ground Water, 43, 434-438.

Paillet, F. L. (1998), Flow modeling and permeability estimation using borehole flow logs in heterogeneous fractured formations, Water Resource Research, $34(5), 997-1010$.

Paillet, F. L. (2000), A field technique for estimating aquifer parameters using flow log data, Ground Water, 38(4), 510-521.

Paillet, F. L. (2004), Borehole flowmeter applications in irregular and largediameter boreholes, Journal of Applied Geophysics, 55, 39-59. (2012), Cross-borehole flow analysis to characterize fracture connections

flowmeter tests for transient heads in heterogeneous aquifers, Ground $W a-$ 
in the Melechov Granite, Bohemian-Moravian Highland, Czech Republic, Hydrogeology Journal, 20(1), 143-154, doi10.1007/s10040-011-0787-1.

Pehme, P.E., B.L. Parker, J.A. Cherry, and J.P. Greenhouse (2010), Improved resolution of ambient flow through fractured rock with temperature logs, Ground Water, 48(2), 191-205.

Pehme, P.E., B.L. Parker, J.A. Cherry, J.W. Molson and J.P. Greenhouse (2013), Enhanced detection of hydraulically active fractures by temperature profiling in lined heated bedrock boreholes, Journal of Hydrology, $48(0), 1-15$.

Perry, H. K. C., C. Jaupart, J.-C. Mareschal, and G. Bienfait (2006), Crustal heat production in the Superior Province, Canadian Shield, and in North America inferred from heat flow data, J. Geophys. Res., 111, B04401, doi10.1029/2005JB003893.

Quinn, P.M., J.A. Cherry, B.L. Parker (2011), Quantification of non-Darcian flow observed during packer testing in fractured rock, Water Resource Resource, 47(9), W09533, doi10.1029/2010WR009681.

Read, T., O. Bour, V. F. Bense, T. Le Borgne, P. Goderniaux, M. Klepikova, R. Hochreutener, N. Lavenant and V. Boschero (2013), Characterizing groundwater flow and heat transport in fractured rock using fiber-optic distributed temperature sensing, Geophysical Research Letters, 40(10), 20552059, doi10.1002/grl.50397.

${ }_{862}$ Reiter, M. (2001), Using precision temperature logs to estimate horizon- 
863

tal and vertical groundwater flow components, Water Resource Research, $37(3), 663-674$.

Saar, M. O. (2011), Review: Geothermal heat as a tracer of large-scale groundwater flow and as a means to determine permeability field, $H y$ drogeology Journal, 19, 31-52.

Sawdey, J.R., and A.S. Reeve (2012), Automated inverse computer modeling of borehole flow data in heterogeneous aquifers, Computers and Geosciences, 46, 219-228.

Silliman, S. and Robinson, R. (1989), Identifying Fracture Interconnections Between Boreholes Using Natural Temperature Profiling: I. Conceptual Basis, Ground Water, 27, 393402, doi10.1111/j.1745-6584.1989.tb00463.x.

Shapiro, A. M. and Hsieh, P. A.(1998), How good are estimates of transmissivity from slug tests in fractured rock?, Ground Water, 36, 37-48.

Sharmeen, R., W. A. Illman, S. J. Berg, T.-C. J. Yeh, Y.-J. Park, E. A. Sudicky, and K. Ando (2012), Transient hydraulic tomography in a fractured dolostone: Laboratory rock block experiments, Water Resource Resource, 48, W10532, doi10.1029/2012WR012216.

Tarantola, A. (2004), Inverse Problem Theory and Model Parameter Estimation, SIAM.

Wagner, V., Li, T., Bayer, P. and Leven, C., Dietrich, P. and Blum, P. (2013), Thermal tracer testing in a sedimentary aquifer: field experiment 
${ }_{884}$ (Lauswiesen, Germany) and numerical simulation, Hydrogeology Journal, 885 doi10.1007/s10040-013-1059-z.

${ }_{886}$ Williams, G. R., G, Brown, W. Hawthorne, A. H. Hartog and P. C. Waite ${ }_{887}$ (2000), Distributed temperature sensing (DTS) to characterize the per888 formance of producing oil wells, Proc. SPIE, Industrial Sensing Systems, $889 \quad$ doihttp://dx.doi.org/10.1117/12.411726.

${ }_{890}$ Yeh T. C. Jim and S. Liu (2000), Hydraulic tomography: Development of a new aquifer test method, Water Resources Research, 36(8), 2095-2105. 


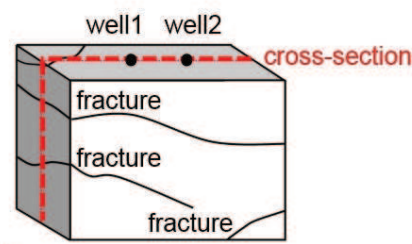

A
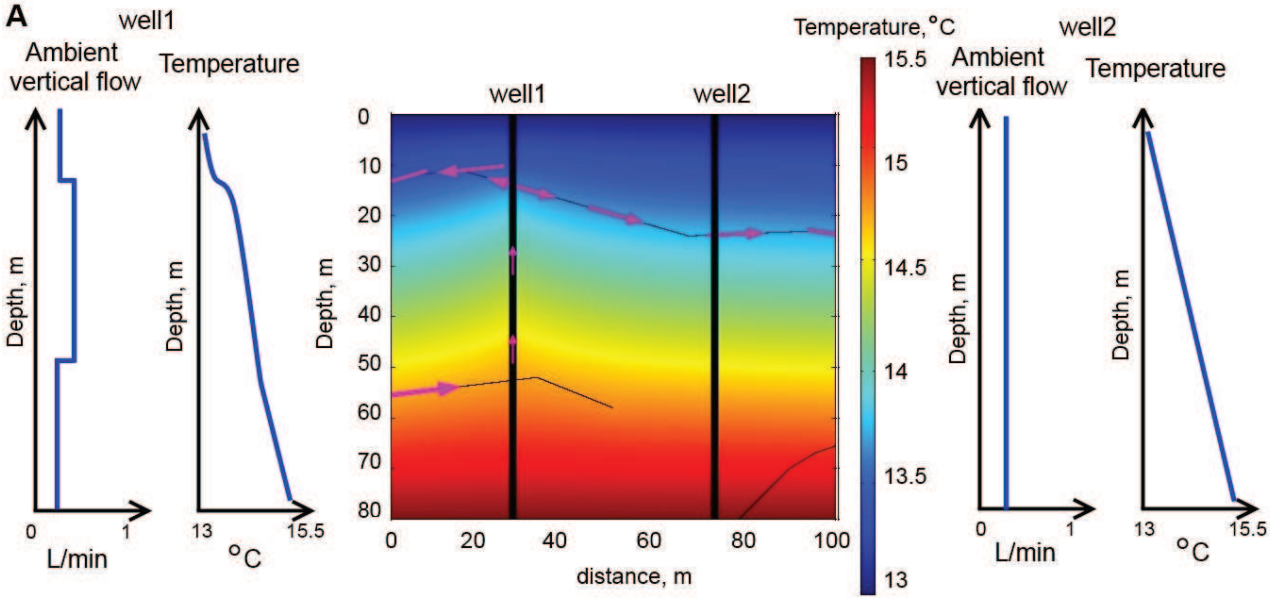

B well1
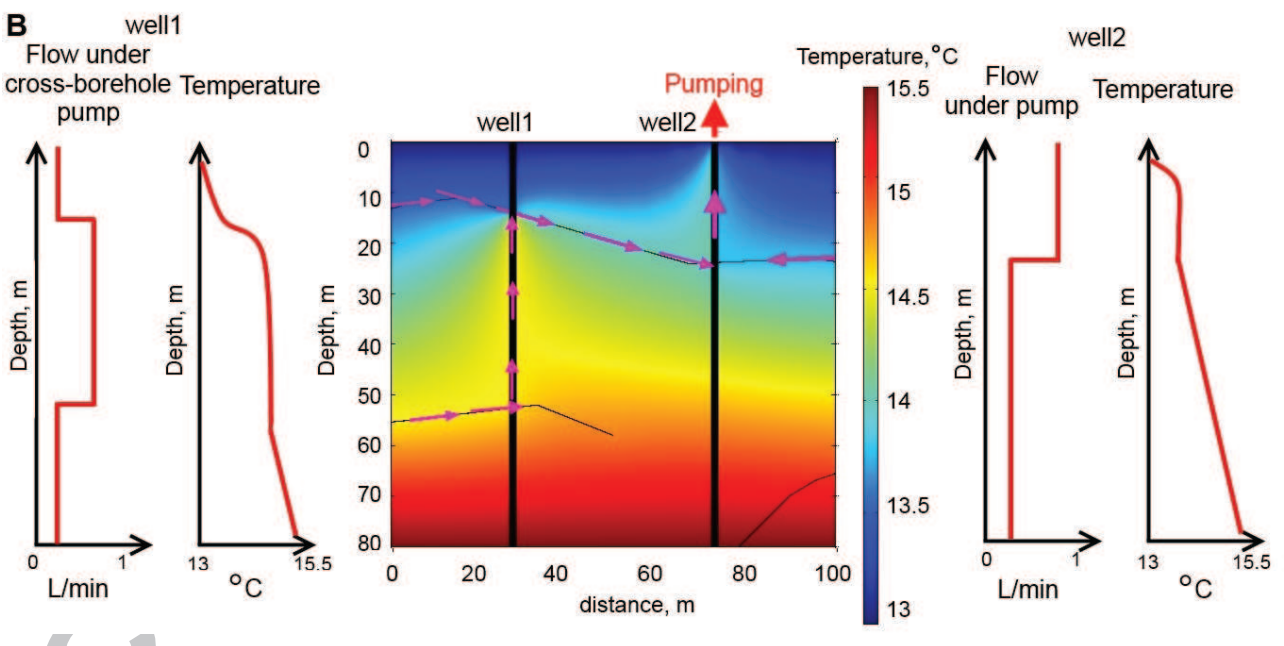

Figure 1: Illustration of a typical groundwater flow and temperature fields for a pair of boreholes connected by one main flow path and intersected by one disconnected fracture each borehole under ambient (A) and pumping (B) flow conditions. The velocity field and temperature field are computed using 2D model. 

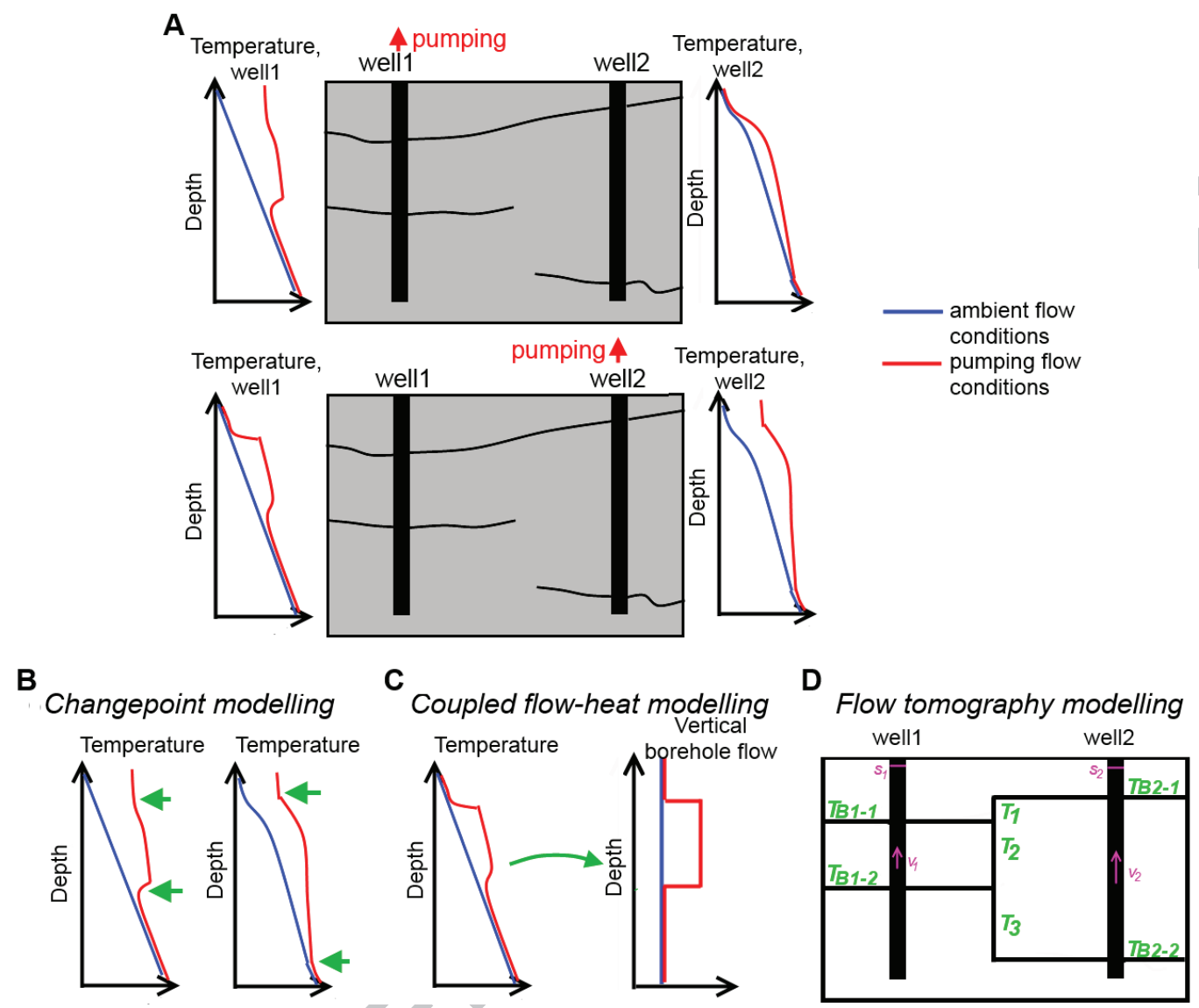

Figure 2: Illustration of the temperature tomography field method conducted in between two boreholes connected by one fracture and intersected by two disconnected fractures (a). Temperature profiles measured under ambient and pumping flow conditions are shown by blue and red correspondingly. Illustration of processing steps of an inverse framework for interpretation of such a data set: (b) automatic fracture detection by applying changepoint modelling; (c) inversion of temperature profiles under ambient, single and cross-borehole flow conditions to derive flow profiles; (d) estimation of fracture hydraulic properties and connectivity between and around a borehole pair by applying flow tomography modelling. 

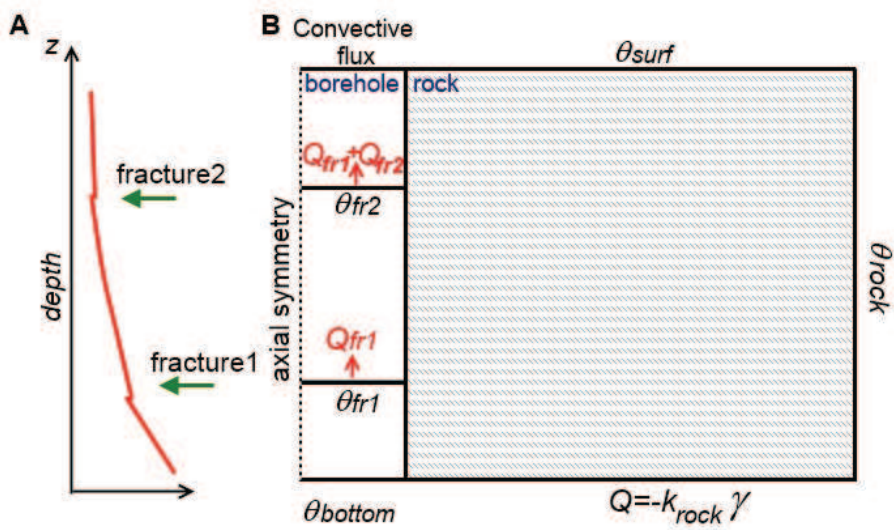

$\frac{1}{8}$

Figure 3: Illustration of the flow and temperature propagation simulation in a borehole. Borehole temperature profile with inferred fracture positions (A) and corresponding heat transfer model boundary conditions (B). We consider the heat diffusion and advection of heat with a constant vertical laminar flow in the borehole and the heat diffusion in the surrounding rock matrix. For each borehole section we impose the borehole flow as the sum of all fractures inflows and outflows $\left(Q_{f r}\right)$ below the modeled section (shown by red). 
A
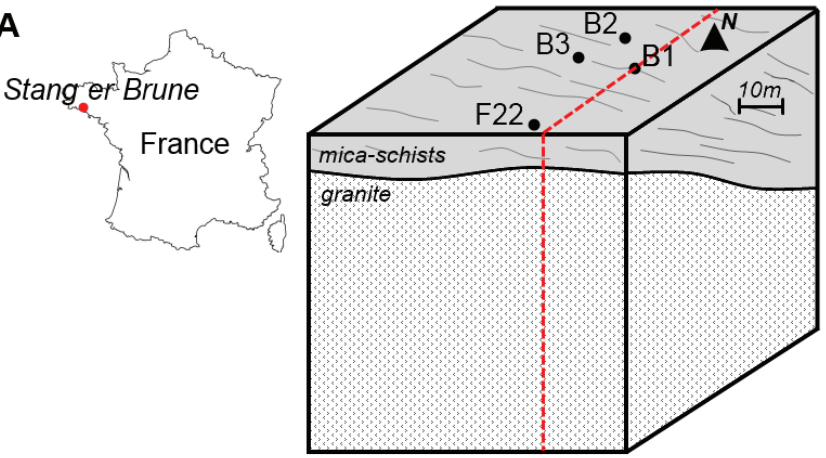

B
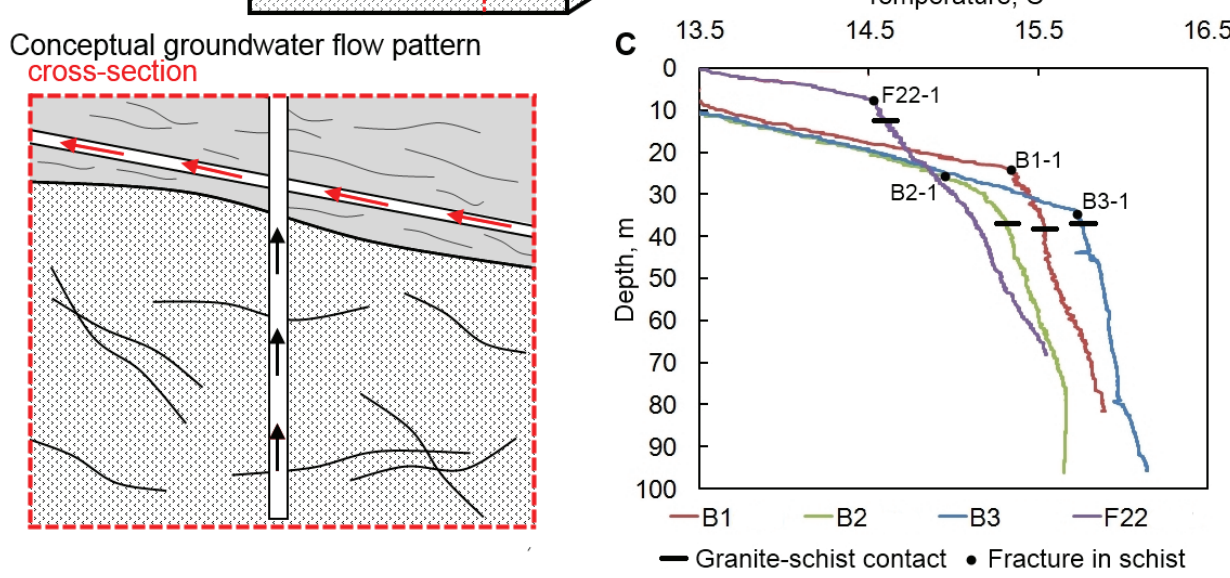

Figure 4: A. Location of the Stang-er-Brune study site, boreholes array configuration and geology of the site. B. Conceptual hydrothermal setting: temperature profile affected by groundwater flow of warmer origin, by localized flow of warmer or cooler origin in narrow fractures and by vertical flow in the borehole itself. C. Temperature profiles measured at the site under the ambient flow conditions. 

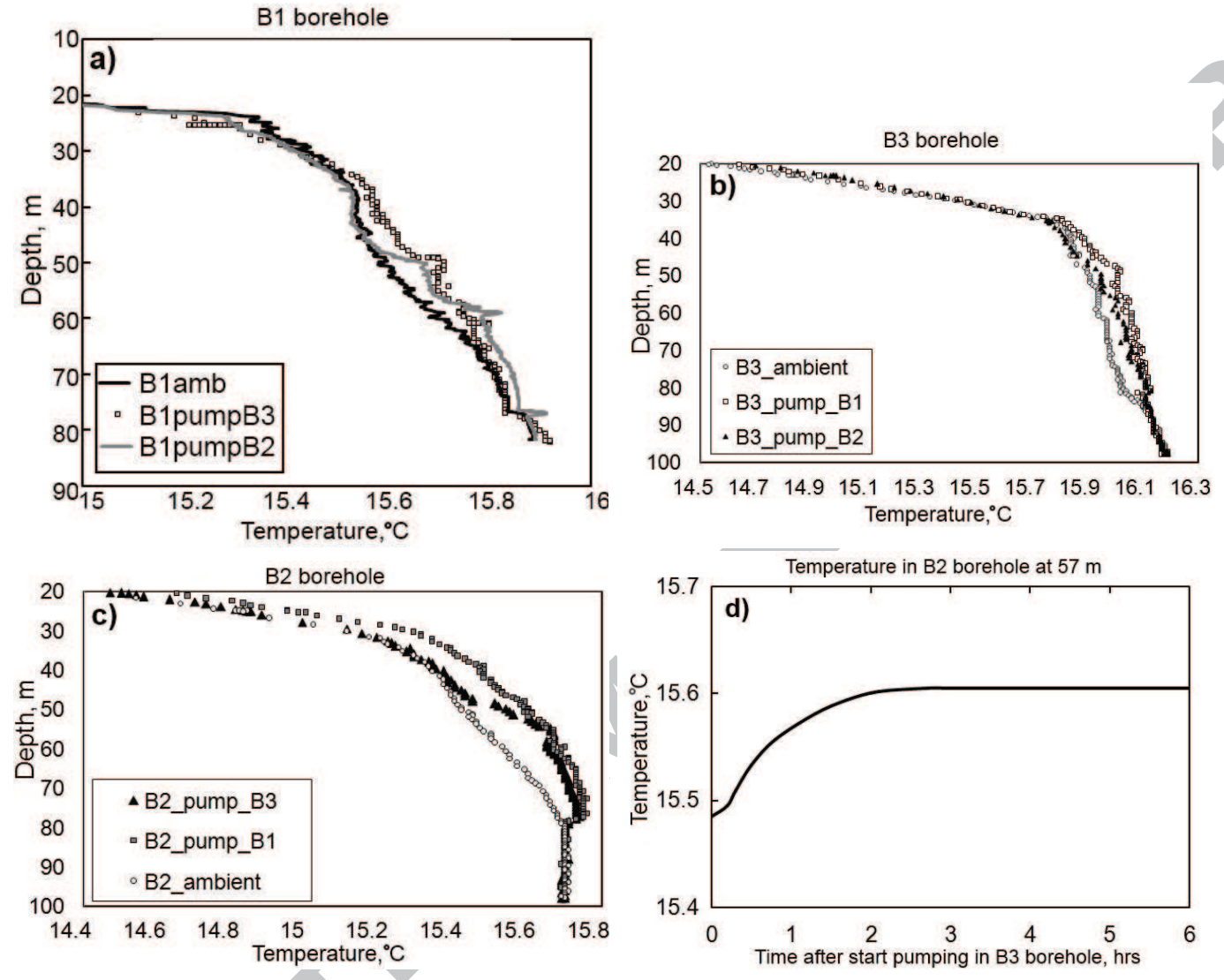

Figure 5: Temperature tomography experiment. Steady-state temperature profiles measured in B1 well when pumping in B2 and B3 wells (a). Steady-state temperature profiles measured in B2 well when pumping in B1 and B3 wells (b). Steady-state temperature profiles measured in B3 well when pumping in B1 and B2 wells (c). Example of temporal evolution of temperature in $\mathrm{B} 2$ at $57 \mathrm{~m}$ depth (d). 
A

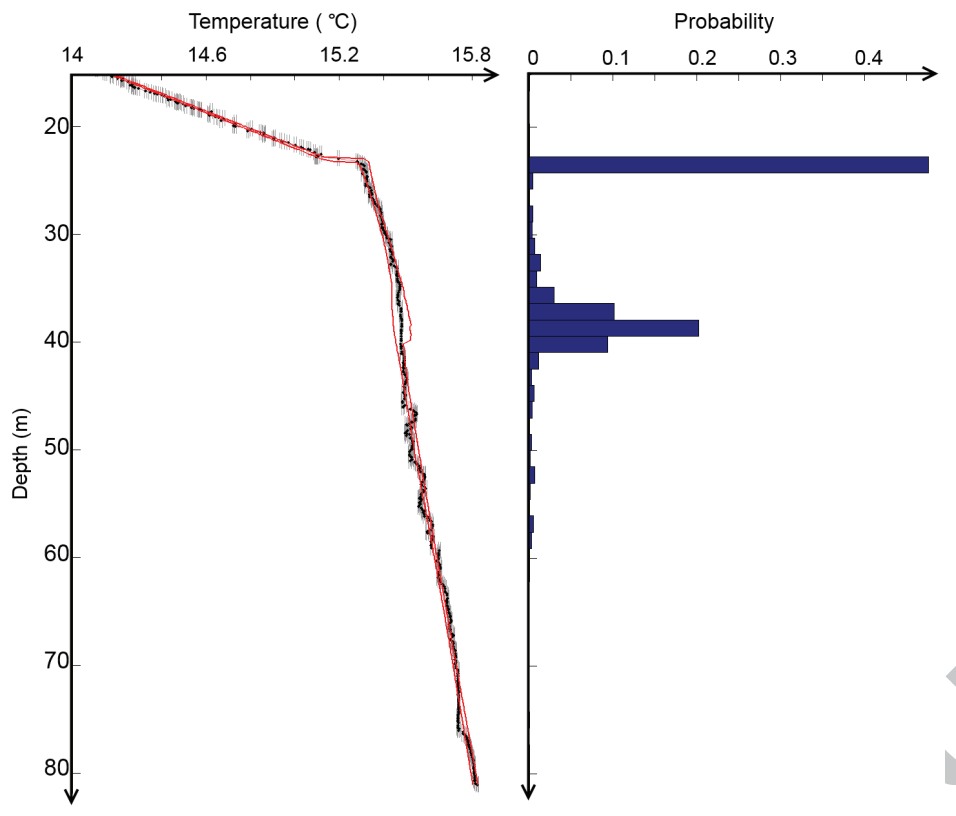

B

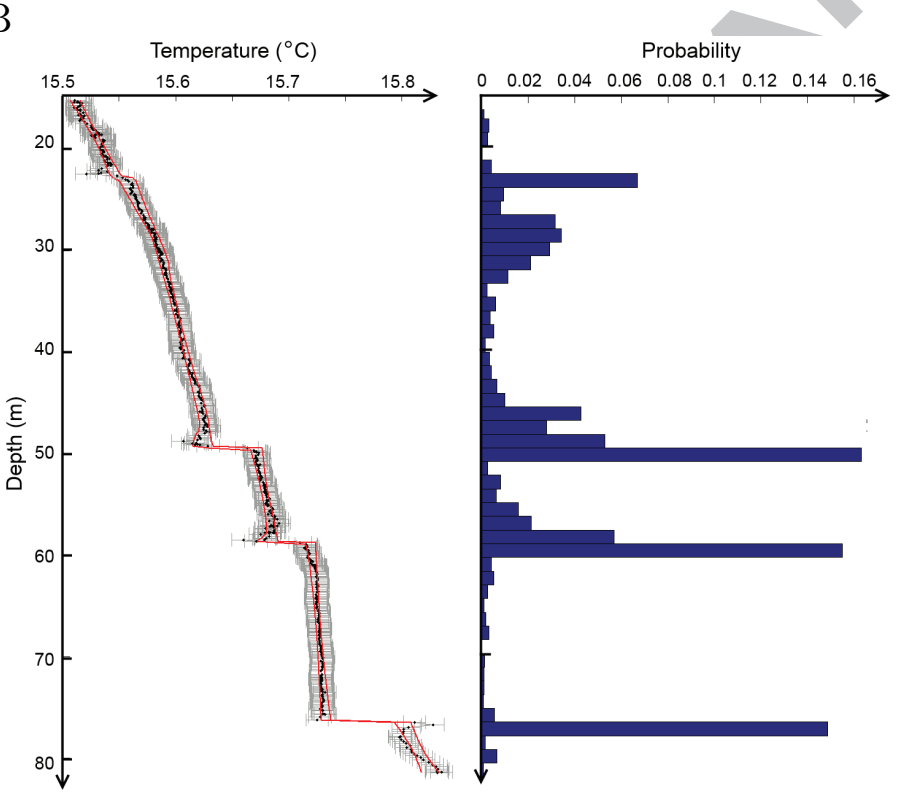

Figure 6: Inferred changepoint models for the temperature profiles measured in B1 borehole under ambient (A) and pumping (B) flow conditions, while pumping at the top of B1 with a pumping rate $Q=20 \mathrm{l} / \mathrm{min}$. The solid red line is the inferred function (relative to the down axis), and the solid black line represents the probability of a changepoint (relative to the upper axis). The error bars are drawn using the mean value of the noise variances for each data set (relative to the down axis). The most probable inferred numbers of changepoints are 2 and 4 respectively. 


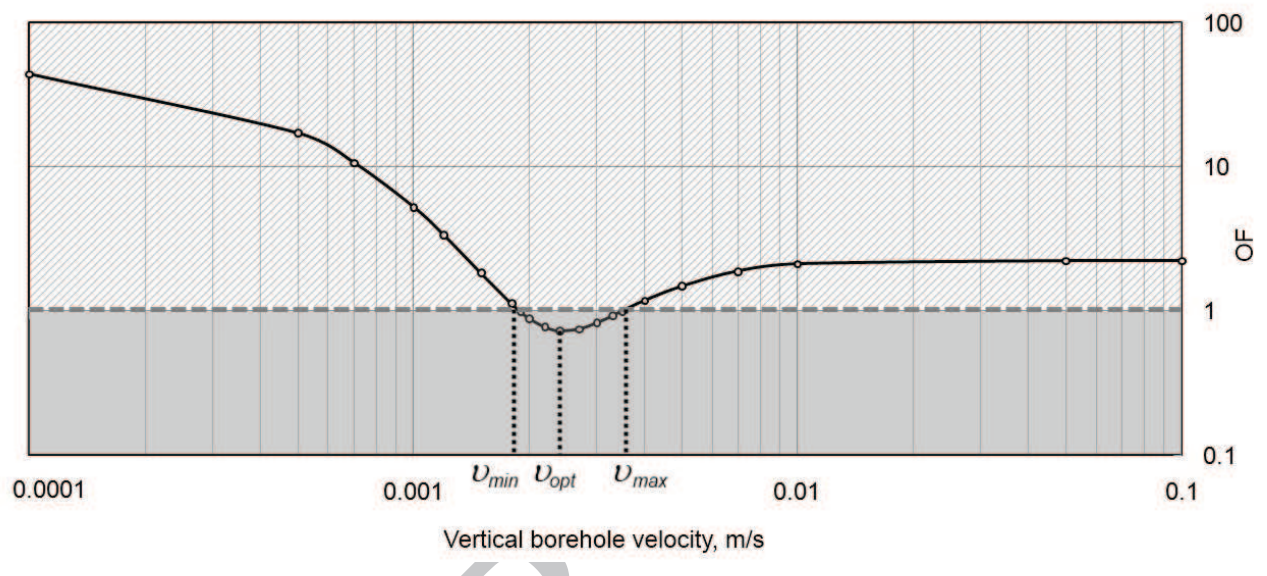

Figure 7: Example of the objective function versus the vertical borehole flow velocity. The minima of the objective function corresponds to the optimal flow velocity $\left(v_{o p t}\right)$, and all the solutions in the range $\left(v_{\min }, v_{\max }\right)$ are acceptable. 


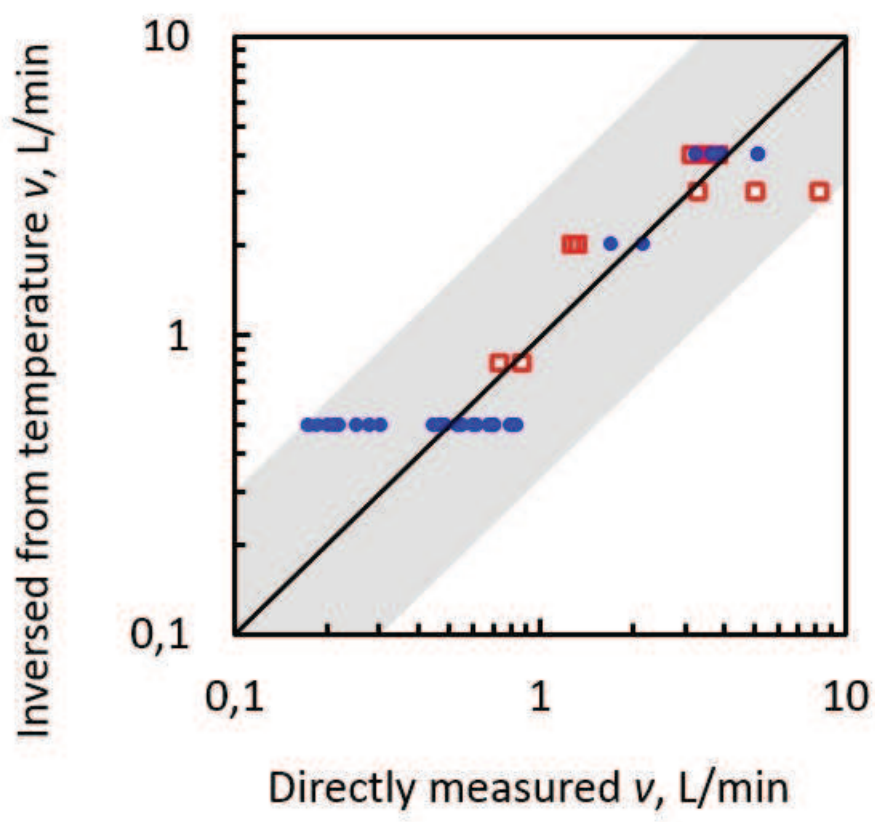

Figure 8: Comparison between flowmeter measurements and velocity values inverted from temperature measurements. Blue markers correspond to ambient flow conditions, while red markers correspond to cross-borehole pumping conditions. Note, that this plot also demonstrates the variability of the flow measurements inside borehole sections due to the tool error and/or variations in borehole diameter. 


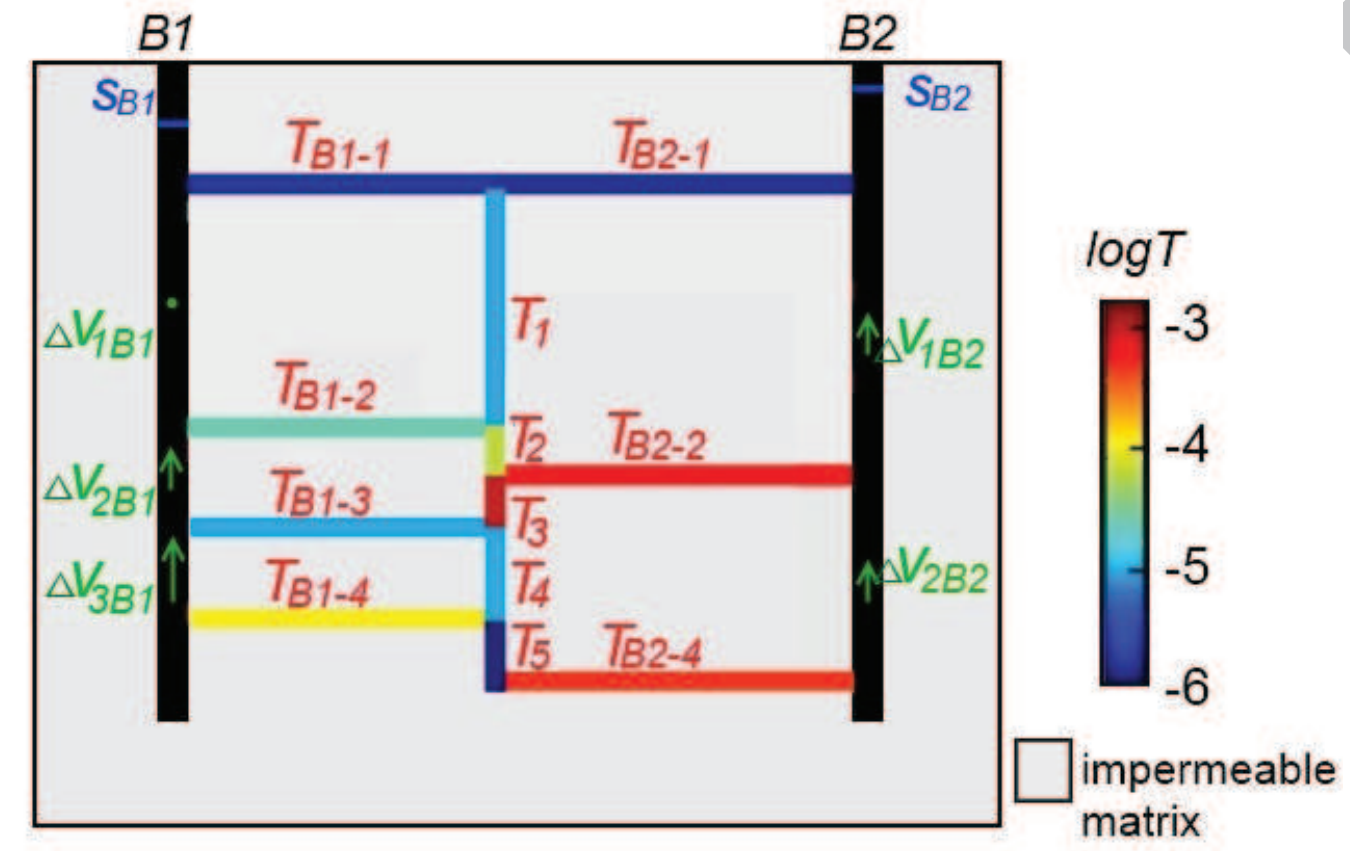

Figure 9: Inferred fracture transmissivities $(T)$ and connectivities between and around B1-B2 borehole pair. Observation well drawdowns during cross-borehole pumping $s$ are shown by blue lines. Variations of vertical velocities during cross-borehole pumping $\Delta v$ in observation boreholes are shown by green arrows. 


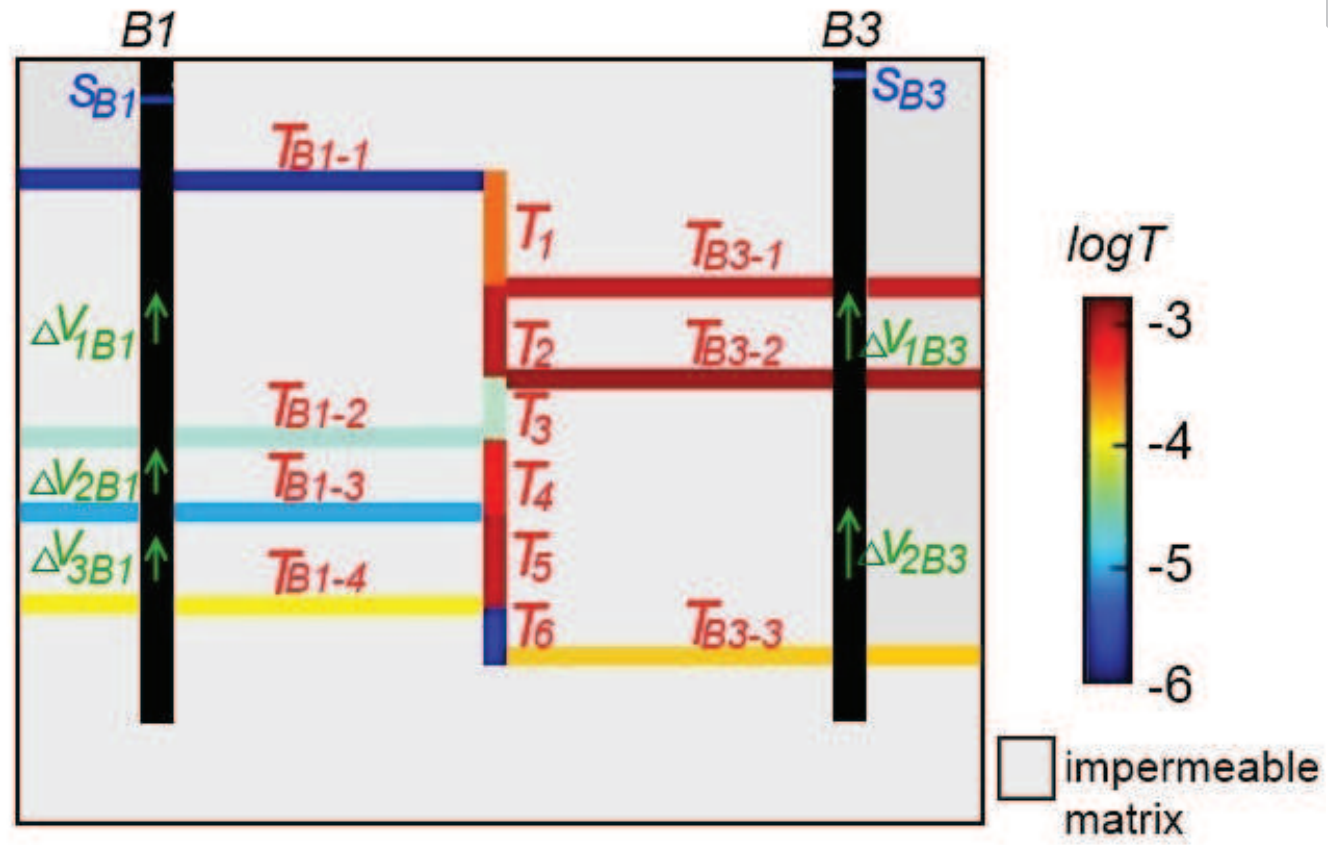

Figure 10: Inferred fracture transmissivities $(T)$ and connectivities between and around B3-B1 borehole pair. Observation well drawdowns during cross-borehole pumping $s$ are shown by blue lines. Variations of vertical velocities during cross-borehole pumping $\Delta v$ in observation boreholes are shown by green arrows. 


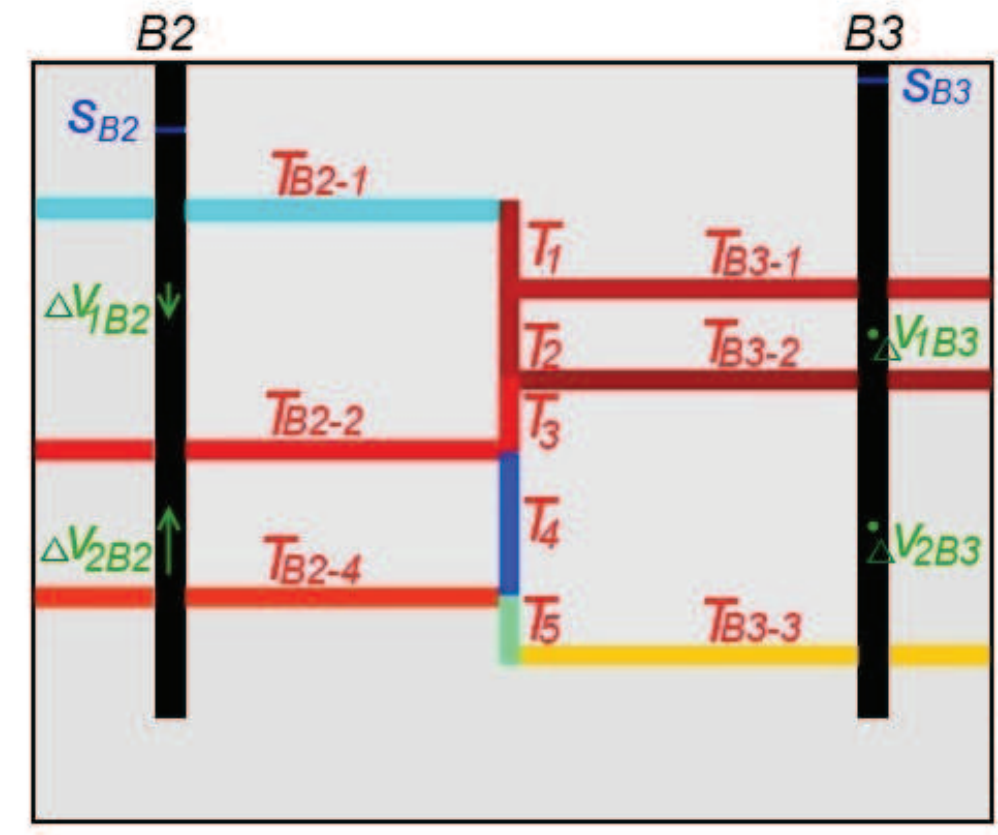

$\log T$

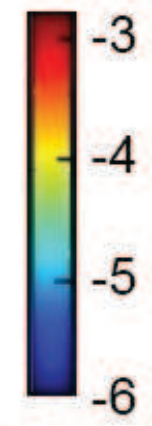

impermeable matrix

Figure 11: Inferred fracture transmissivities $(T)$ and connectivities between and around B2-B3 borehole pair. Observation well drawdowns during cross-borehole pumping $s$ are shown by blue lines. Variations of vertical velocities during cross-borehole pumping $\Delta v$ in observation boreholes are shown by green arrows. 
Table 1: Inferred fracture transmissivities. We utilized ambient and steady pumping single-borehole flow profiles and drawdowms in order to infer local fracture transmissivities and cross-borehole flow profiles and drawdowns were used for inversion of connected fracture transmissivities.

\begin{tabular}{|c|c|c|c|c|}
\hline Scale & Well & $\begin{array}{l}\text { Data used for in- } \\
\text { version }\end{array}$ & Fracture & $T, m^{2} / s$ \\
\hline \multirow{3}{*}{$\begin{array}{l}\text { Transmissivities of } \\
\text { the main fractures in } \\
\text { the near field }\end{array}$} & B1 & $\begin{array}{l}1 \text { drawdown, } 3 \\
\text { velocities }\end{array}$ & $\begin{array}{l}T_{B 1-1} \\
T_{B 1-2} \\
T_{B 1-3} \\
T_{B 1-4} \\
\end{array}$ & $\begin{array}{l}2 \cdot 10^{-6} \\
4 \cdot 10^{-5} \\
1.3 \cdot 10^{-5} \\
1.6 \cdot 10^{-4}\end{array}$ \\
\hline & B2 & $\begin{array}{l}1 \text { drawdowns, } 2 \\
\text { velocities }\end{array}$ & $\begin{array}{l}T_{B 2-1} \\
T_{B 2-2} \\
T_{B 2-4}\end{array}$ & $\begin{array}{l}2 \cdot 10^{-6} \\
8 \cdot 10^{-4} \\
5 \cdot 10^{-4}\end{array}$ \\
\hline & B3 & $\begin{array}{l}1 \text { drawdowns, } 2 \\
\text { velocities }\end{array}$ & $\begin{array}{l}T_{B 3-1} \\
T_{B 3-2} \\
T_{B 3-3}\end{array}$ & $\begin{array}{l}8 \cdot 10^{-4} \\
1.3 \cdot 10^{-3} \\
1.6 \cdot 10^{-4}\end{array}$ \\
\hline \multirow{3}{*}{$\begin{array}{l}\text { Transmissivities of } \\
\text { the main connected } \\
\text { fractures }\end{array}$} & \multirow[b]{2}{*}{ B1-B3 } & \multirow[b]{2}{*}{$\begin{array}{l}2 \text { drawdowns, } 5 \\
\text { velocities }\end{array}$} & $\begin{array}{l}T_{1} \\
T_{2} \\
T_{3} \\
T_{4} \\
T_{5}\end{array}$ & $\begin{array}{l}1.3 \cdot 10^{-5} \\
8 \cdot 10^{-5} \\
1.6 \cdot 10^{-3} \\
1.3 \cdot 10^{-5} \\
1.6 \cdot 10^{-6}\end{array}$ \\
\hline & & & $\begin{array}{l}T_{1} \\
T_{2} \\
T_{3} \\
T_{4} \\
T_{5} \\
T_{6}\end{array}$ & $\begin{array}{l}3.2 \cdot 10^{-4} \\
1 \cdot 10^{-3} \\
3.2 \cdot 10^{-5} \\
5 \cdot 10^{-4} \\
1 \cdot 10^{-3} \\
2.5 \cdot 10^{-6}\end{array}$ \\
\hline & B2-B3 & $\begin{array}{l}2 \text { drawdown, } 4 \\
\text { velocities }\end{array}$ & $\begin{array}{l}T_{1} \\
T_{2} \\
T_{3} \\
T_{4} \\
T_{5}\end{array}$ & $\begin{array}{l}1 \cdot 10^{-3} \\
1 \cdot 10^{-3} \\
6.3 \cdot 10^{-4} \\
4 \cdot 10^{-6} \\
3.2 \cdot 10^{-5}\end{array}$ \\
\hline
\end{tabular}


Table 2: Comparison of flow tomography data, inverted from temperature measurements, with numerical solutions that best matches the data. Flow tomography data include drawdowns $s$ and variations of vertical borehole flow velocities $\Delta v$ during cross-borehole pumping in observation boreholes. The values of fracture transmissivities that yield the best match to the data are presented in Figure 9 for B1-B2 borehole pair, in Figure 10 for B1-B3 borehole pair and in Figure 11 for B2-B3 borehole pair. The corresponding data errors are $\sigma_{v}=1 \mathrm{~mm} / \mathrm{s}$ and $\sigma_{s}=2 \mathrm{~cm}$ for flow and drawdown respectively.

\begin{tabular}{|c|c|c|c|c|}
\hline $\begin{array}{l}\text { Borehole } \\
\text { pair }\end{array}$ & Observation & $\begin{array}{l}\text { Flow tomogra- } \\
\text { phy data }\end{array}$ & $\begin{array}{l}\text { Best match to } \\
\text { the data }\end{array}$ & $\begin{array}{l}\text { OF } \\
\text { value }\end{array}$ \\
\hline \multirow{7}{*}{ B1-B2 } & $s_{B 1}, \mathrm{~cm}$ & 34 & 29 & \multirow{7}{*}{3.7} \\
\hline & $s_{B 2}, \mathrm{~cm}$ & 15 & 15 & \\
\hline & $\Delta v_{1 B 1}, \mathrm{~mm} / \mathrm{s}$ & 0 & 0 & \\
\hline & $\Delta v_{2 B 1}, \mathrm{~mm} / \mathrm{s}$ & 1 & 1 & \\
\hline & $\Delta v_{3 B 1}, \mathrm{~mm} / \mathrm{s}$ & 3 & 1.3 & \\
\hline & $\Delta v_{1 B 2}, \mathrm{~mm} / \mathrm{s}$ & 1.1 & 0.5 & \\
\hline & $\Delta v_{2 B 2}, \mathrm{~mm} / \mathrm{s}$ & 1.1 & 1.3 & \\
\hline \multirow{13}{*}{ B1-B3 } & $s_{B 1}, \mathrm{~cm}$ & 19 & 16 & \multirow{7}{*}{6.35} \\
\hline & $s_{B 3}, \mathrm{~cm}$ & 2 & 7 & \\
\hline & $\Delta v_{1 B 1}, \mathrm{~mm} / \mathrm{s}$ & 1.4 & 0 & \\
\hline & $\Delta v_{2 B 1}, \mathrm{~mm} / \mathrm{s}$ & 1.4 & 0 & \\
\hline & $\Delta v_{3 B 1}, \mathrm{~mm} / \mathrm{s}$ & 1.4 & 0.5 & \\
\hline & $\Delta v_{1 B 3}, \mathrm{~mm} / \mathrm{s}$ & 2.8 & 0.5 & \\
\hline & $\Delta v_{2 B 3}, \mathrm{~mm} / \mathrm{s}$ & 2.8 & 3.4 & \\
\hline & & 14 & 14.9 & \multirow{6}{*}{1.05} \\
\hline & $s_{B 3}, \mathrm{~cm}$ & 18 & 16 & \\
\hline & $\Delta v_{1 B 2}, \mathrm{~mm} / \mathrm{s}$ & -0.8 & 0 & \\
\hline & $\Delta v_{2 B 2}, \mathrm{~mm} / \mathrm{s}$ & 1.4 & 1 & \\
\hline & $\Delta v_{1 B 3}, \mathrm{~mm} / \mathrm{s}$ & 0 & -1 & \\
\hline & $\Delta v_{2 B 3}, \mathrm{~mm} / \mathrm{s}$ & 0 & 0 & \\
\hline
\end{tabular}




\section{Highlights}

- Temperature tomography is proposed as a new method for characterizing fractured media

- We propose an inverse multi-step framework to interpret borehole temperature profiles

- We automatically detect permeable fractures from borehole temperature profiles

- We produce flow profiles by inversion of temperature profiles

- We inverse flow profiles to infer fracture transmissivities and connectivity 